\title{
Role Centrality and Shared Activities with Grandchildren: Effects on Grandparent Wellbeing
}

\author{
Madeline Marie Marello \\ West Virginia University, mmm0108@mix.wvu.edu
}

Follow this and additional works at: https://researchrepository.wvu.edu/etd

Part of the Developmental Psychology Commons, Geropsychology Commons, and the Social Psychology Commons

\section{Recommended Citation}

Marello, Madeline Marie, "Role Centrality and Shared Activities with Grandchildren: Effects on Grandparent Wellbeing" (2020). Graduate Theses, Dissertations, and Problem Reports. 7799.

https://researchrepository.wvu.edu/etd/7799

This Thesis is protected by copyright and/or related rights. It has been brought to you by the The Research Repository @ WVU with permission from the rights-holder(s). You are free to use this Thesis in any way that is permitted by the copyright and related rights legislation that applies to your use. For other uses you must obtain permission from the rights-holder(s) directly, unless additional rights are indicated by a Creative Commons license in the record and/ or on the work itself. This Thesis has been accepted for inclusion in WVU Graduate Theses, Dissertations, and Problem Reports collection by an authorized administrator of The Research Repository @ WVU. For more information, please contact researchrepository@mail.wvu.edu. 
Role Centrality and Shared Activities with Grandchildren: Effects on Grandparent Wellbeing

Madeline M. Marello

\author{
Master's Thesis submitted \\ to the Eberly College of Arts and Science \\ at West Virginia University \\ in partial fulfillment of the requirements for the degree of \\ Masters of Science in \\ Psychology of Life Span Development
}

Julie Hicks Patrick, Ph.D., Chair

Constance Toffle, Ph.D.

Amy E. Fiske, Ph.D.

Department of Psychology

Morgantown, West Virginia

2020

Keywords: Grandparenting; Custodial Grandparents; Role Centrality; Moderated

Regression; Family Relationships

Copyright 2020 Madeline M. Marello 


\begin{abstract}
Role Centrality and Shared Activities with Grandchildren: Effects on Grandparent Wellbeing
\end{abstract}

\title{
Madeline M. Marello
}

Research shows that physical and mental health are closely linked (Ohrnberger, Fichera, \& Sutton, 2017). Further, social role theory states that holding and enacting valued roles, such as grandparenting, can buffer the negative effects of health on depression (Reitzes \& Mutran, 2004). Using data from 247 grandparents (Mean age $=66.5$; range 42 to 90 years; $46.2 \%$ grandfathers), we examined whether grandparent role centrality and engagement with grandchildren altered the effects of physical health on depression. We then explored model differences between 164 custodial and 83 traditional grandparents.

We found that for all grandparents the model was of sufficient fit: $X^{2}(\mathrm{DF}=12, \mathrm{~N}=247)=$ $39.15, \mathrm{p}<.001 ; \mathrm{R} 2=.236 ; \mathrm{CMIN} / \mathrm{DF}=3.26, \mathrm{TLI}=.955$, and $\mathrm{RMSEA}=.068$. Inspection of the individual regression paths showed that among the full sample, significant main effects for Role Centrality $(\beta=.699 * * *)$ and Activities $(\beta=-.768 * * *)$ on Depression were detected. However, significant main effects for Subjective Health $(\beta=-.034)$ did not emerge. All interactions were significant in predicting depression, the three-way interaction term Subjective Health, Role Centrality, and Activities additionally accounted for depression variance $\left(\beta=-1.062^{* * *}\right)$.

We then examined whether the paths were moderated by custodial status. The model accounted for $25.7 \%$ of depression among traditional grandparents, however, no paths emerged as significant. The model accounted for $36.8 \%$ of depression among custodial grandparents, and all paths were significant. Among custodial grandparents, there were significant effects on Depression from Subjective Health $(\beta=.439 * * *)$, with main effects for Role Centrality $(\beta=-$ $\left..635^{* *}\right)$ and Activities $\left(\beta=-.711^{* *}\right)$. Moreover, each interaction term also emerged as significant with the 3-way interaction of Health, Role Centrality, and Activities accounting for additional variance in depression $\left(\beta=-.445^{*}\right)$. Custodial grandparents in poorer health who valued the grandparent role and those in poorer health who engaged with their grandchildren experienced fewer depressive symptoms than grandparents who do not engage with grandchildren. Results are discussed in terms of the need to examine the differences of family/social contexts in grandparent populations. 


\section{Table of Contents}

Chapter 1: Introduction and Literature Review............................................................ 1

Predictors of Role Centrality .................................................................................. 3

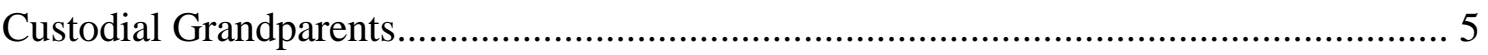

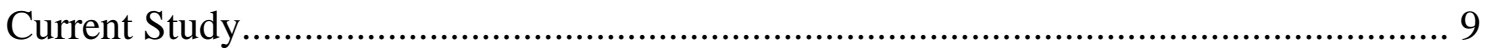

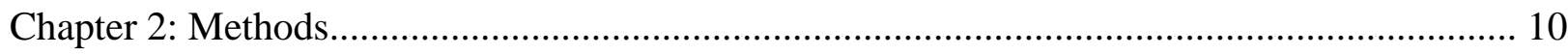

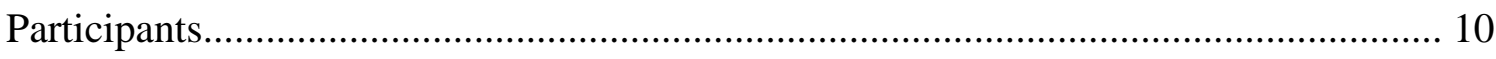

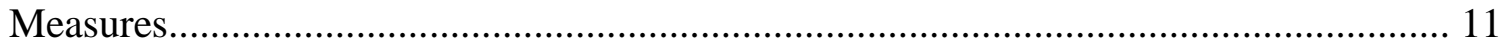

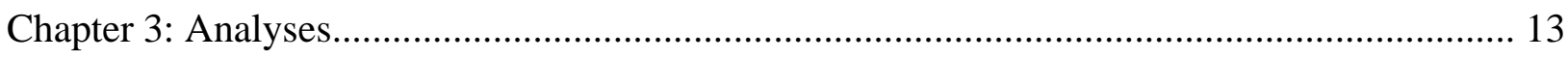

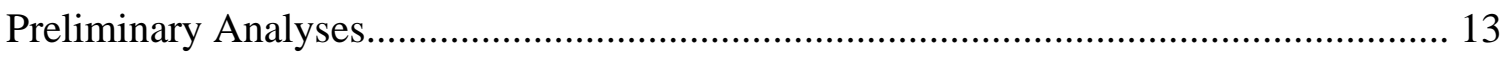

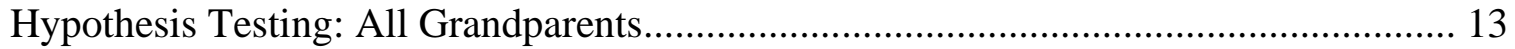

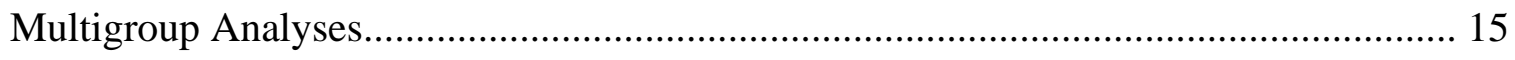

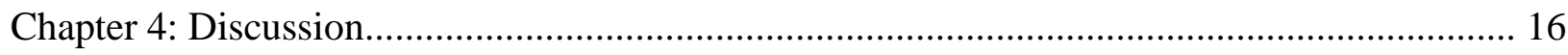

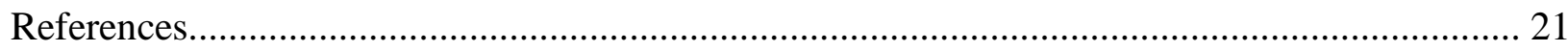

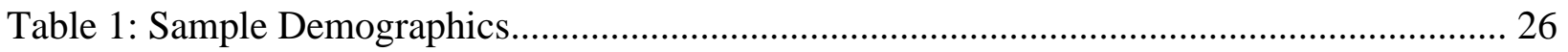

Table 2: Scale Means, Standard Deviations, and Cronbach's Alpha...................................... 27

Table 3: Path Analyses for Entire Sample................................................................. 28

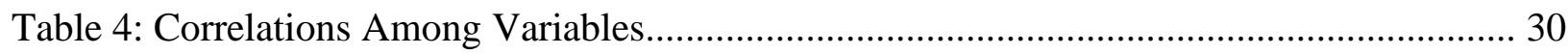

Table 5: Path Analysis for Traditional Grandparents.................................................... 31

Table 6: Path Analysis for Custodial Grandparents......................................................... 33

Figure 1: Conceptual Model of a Moderated Moderation.................................................... 35

Figure 2: Tested Pathways for the Moderated Moderation................................................... 36

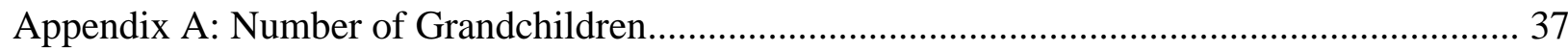

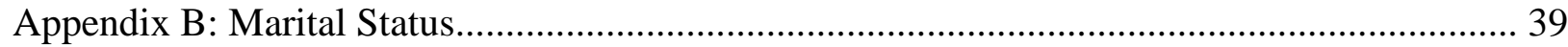

Appendix C: Paths Across Groups Comparison............................................................ 41

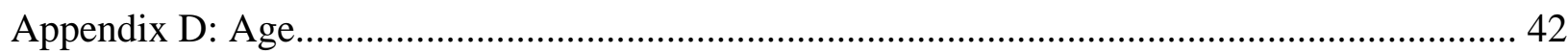

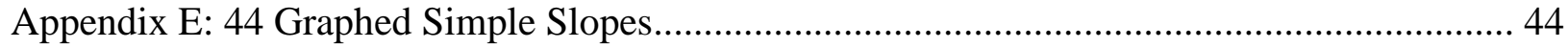

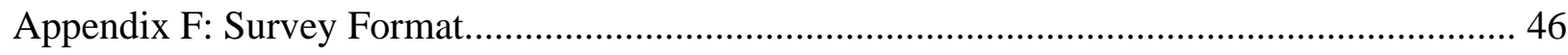




\section{Role Centrality and Shared Activities with Grandchildren: Effects on Grandparent Wellbeing}

Wellbeing is composed of both physical and emotional health; these two health domains have a strong relation (Diener, 1984; Lawton, Moss, Fulcomer, \& Kleban, 1982). Earlier studies have found that individuals with poor physical health, especially those living with a chronic physical condition, are at three times the risk of also having depression (Goldberg, 2010; Moussavi et al., 2007). Experiencing poor physical or emotional health can then lead to poor health in the other domain. Research shows that the relationship between physical health and mental health is reciprocal: depression can lead to negative physical health, just as poor physical health can increase the risk of depression (Ohrnberger, Fichera, \& Sutton, 2017). Depression has been shown to exacerbate the negative effects of poor physical health: individuals with chronic obstructive pulmonary disease occurring with depression had significantly lower health-related quality of life compared to those without depression (Moy et al., 2009). In a study of adults with arthritis who were also experiencing depression those who were given an intervention to improve mood experienced less pain, less interference with daily activities because of arthritis, and less interference with daily activities because of pain compared to those who did not receive depression treatment (Lin et al., 2003).

Older adults are more likely to experience decreased physical health, putting them at an increased risk for poor mental health, such as depression (Lin et al., 2003; Moussavi et al., 2007; Ohrnberger et al., 2017). Ohrnberger and associates (2017) found that the frequency of social interaction had a positive effect on both physical health and mental health. Because physical health and mental health are linked, intervention could improve both. The lives of older adults in 
poor physical health, experiencing depression could be improved by focusing on valued social roles and meaningful emotional activities (Carstensen et al., 1999; Reitzes \& Mutan, 2004).

Valued roles are central to a person's identity and add significant meaning to their existence (Muller \& Litwin, 2011; Reitzes \& Mutran, 2004). Social role theory explains that there is a link between social roles and personal identity, which can influence a person's perceptions of wellbeing (George, 1990). The ability to fulfill role-related expectations creates a sense of meaning or purpose in life which contributes to one's psychological wellbeing (Thoits, 1991). The more central a role is, the more important and influential that social role can be for a person's wellbeing. In fact, enacting a central role (fulfilling role-related expectations) has been linked to better psychological well-being, especially so for family roles like being a grandparent (Drew \& Silverstein, 2004). If someone has a central grandparent role, it may be possible to utilize this role to combat depressive symptoms and improve mental wellbeing.

The influence of valued social roles may be especially important for older adults. For example, the socioemotional selectivity theory states that as individuals age, and their future time perspective shortens, life goals change from knowledge-seeking to emotional regulation and satisfaction (Carstensen, 1995). Older adults' social relationships become especially crucial for the management of their emotions, and individuals begin to narrow in on meaningful social relationships. Some of the identified most important social roles for older adults include being a spouse, a parent, and a grandparent; these roles have been shown to impact life satisfaction and wellbeing more so than other less salient roles (Krause, 1994). A potentially useful relationship for an older adult could be their relationship with their grandchildren (Mahne \& Huxhold, 2015). Through the combination of enacting a valued role of being a grandparent and fostering a meaningful relationship with a grandchild, older adults may be able to improve their wellbeing. 
Grandparenting is an ascribed role in that others' actions are responsible for whether or not one becomes a grandparent. However, there are a variety of ways in which one may enact the grandparenting role (Patrick \& Goedereis, 2009). For example, there have been changes to the demographics of the aging grandparent population. Some grandparents deviate from traditional grandparent-grandchild interactions, such as grandparents not interacting with grandchildren, communicating only digitally with grandchildren, or even raising grandchildren and having custody over them (Hayslip et al., 1998; Muller \& Litwin, 2011; Reitzes \& Mutran, 2004). Older adults can enact their grandparent social role with grandchildren through many different routes: communication, activities, keeping in contact, and spending time together. The frequency of contact that grandparents actually have with their grandchildren can depend heavily on the middle generation of parents (Mahne \& Huxhold, 2015). In this situation, parents can act as gatekeepers for grandparent access to grandchildren, which can thus influence the frequency of contact and quality of grandparent-grandchild relationships. Previous research examining central social roles has found that grandparent role centrality is a positive and helpful quality for grandparents. One study of 203 grandparents found that those who reported centrality of the grandparent role were more likely to find satisfaction and fulfillment from that role (Reitzes \& Mutran, 2004).

\section{Predictors of Role Centrality}

If a social role is central and a part of one's identity, a person is more likely to be actively engaged with that role (Reitzes \& Mutran, 2004). A person may have multiple social roles, but often only one or two roles are truly central for the individual and will be enacted on (Muller \& Liwin, 2011). For a grandparent role, contact with grandchildren is a critical dimension to examine as grandparents who have grandparent role centrality will be spending more time with 
grandchildren and building up their relationship (Hayslip et al., 2003). Multiple studies show that more time spent together increases the quality of relationships between grandparents and grandchildren and that this has healthy outcomes. Mahne and Huxhold (2015) found that higher relationship quality between grandparents and grandchildren was related to higher subjective wellbeing for grandparents. Additionally, grandparents who had higher-quality relationships with grandchildren also had high life satisfaction and higher positive affect, regardless of their educational level (Mahne \& Huxhold, 2015).

There may be gender differences in how grandparent role centrality and contact with grandchildren interact. In a sample of urban grandparents, most grandmothers had stable grandparent centrality; however, for grandfathers, their role centrality was influenced by interacting with grandchildren. In the repeated measures study, grandfathers who had a higher frequency of contact with grandchildren also had increased levels of grandparent role centrality (Reitzes \& Mutran, 2004). It may be possible that for some grandparents quality time with grandchildren initiates the centrality of their role, while for others it is their central grandparent role initiating their efforts on spending time with grandchildren.

Besides a central grandparent role, there can be many other factors that influence one's frequency of contact with grandchildren. Uhlenberg and Hammill (1998) identified that the number of households that grandchildren reside in, called grandchildren sets, influenced grandparent contact with grandchildren. If a grandparent had multiple children, and those parents had their own children, there would be multiple households of grandchildren to interact with. Researchers found that grandparents who have more grandchildren-sets are likely to have overall more contact with grandchildren but have infrequent contact with a particular set of grandchildren. The gender of the grandparent and parent is also related to the frequency of 
contact with grandchildren; maternal grandmothers are more likely to have frequent contact with their grandchildren than paternal grandfathers (Uhlenberg \& Hammill, 1998). It seems that females are the connective social links between generations, as being a woman and having a daughter dramatically increases the likelihood of intergenerational contact between grandmothers and grandchildren. Additionally, married grandparents were found to have more frequent contact with grandchildren than non-married grandparents. With the combination of gender and marital status, non-married grandfathers are least likely to maintain contact with grandchildren. While, married grandmothers are the most likely to maintain contact with grandchildren, especially if they have a daughter with her own children (Uhlenberg \& Hammill, 1998).

One obstacle for maintaining frequent contact with grandchildren is the geographical distance, as grandparents who live further away have less contact with grandchildren. An important finding to note was that neither poor health nor being in the workforce interfered with the frequency of contact with grandchildren (Uhlenberg \& Hammill, 1998).

\section{Custodial Grandparents}

Most literature on grandparents involves those with traditional grandparent roles as their sample, meaning that grandparents are living outside the home of their grandchildren and are not the primary caretaker of their grandchildren. However, these findings for traditional grandparents may not extend predictions or findings to a growing population of custodial grandparents, who are grandparents which are the primary caretakers of their grandchildren. In some cases, grandparents have full legal custody of grandchildren, while others may be primary caretakers without official legal guardianship. An important consideration is that grandparents often become custodial guardians because of adverse situations. Parents may not be able to take on the 
parent role themselves because of numerous reasons, such as death, drug abuse, incarceration, mental or physical illness, economic problems, or maltreatment of the child, either abuse or abandonment (Nadorff \& Patrick, 2018; Pittman \& Boswell, 2007; Poehlmann et al., 2008; Smith \& Palmieri, 2007). In addition to the rise of drug problems facing many families today, additional forces outside the home have also increased the occurrence of custodial grandparenting. Governments have changed policies to decrease child welfare by prioritizing children to be supported by next of kin. Both the United States and the United Kingdom have made recent efforts to reduce the number of children supported by government money (Glaser et al., 2018). This results in grandparents stepping up and taking care of children that would otherwise be in foster care or another form of government-supported childcare.

Traditional grandparents' contact with grandchildren may range from simple fun activities to occasional caretaking, like babysitting. However, for custodial grandparents contact with grandchildren will always include some caretaking and likely discipline, as they must take on the role of a parent and primary caregiver. This change in the relationship also alters what one is doing when in contact with grandchildren (Hayslip et al., 1998). Based on the nature of custodial grandparents, they are going to be spending more time with grandchildren. Additionally, custodial grandparents are likely to also have different types of contact with grandchildren since they spend a significant amount of time being caretakers. The frequency and form of contact between grandparents and grandchildren may vary based on custodial status.

How one enacts the grandparent role, whether it be focused on caretaking or fun activities, could influence the association between physical health and depression. A study examining the differences between custodial and traditional grandparents found that for traditional grandparents $(n=92,80 \%$ female) role satisfaction was related to fewer 
responsibilities of caregiver and higher relationship quality with the grandchild (Hayslip, Temple, Shore, \& Henderson, 2006). As previously discussed, relationship quality relates to social role satisfaction, and this association was also found for custodial grandparents whose role satisfaction was related to higher well-being and greater relationship quality with their grandchild (Hayslip et al., 2006). Another difference between custodial and traditional grandparenting is the number of responsibilities, with traditional grandparents benefiting from fewer grandchild responsibilities and custodial grandparents unable to experience fewer responsibilities. However, despite the increased responsibility for custodial grandparents, some custodial grandfathers were able to glean greater meaning and value from the social role compared to traditional grandparents (Hayslip, Shore, Henderson, \& Lambert, 1998).

Hayslip and colleagues (2006) determined that relationship quality with grandchildren was an indicator of role satisfaction for both custodial and traditional grandparents and that those with an active and positive relationship with their grandchildren have greater fulfillment from their grandparent role. Even for custodial grandparents, spending more time with grandchildren was linked to higher satisfaction of their social role, possibly because they were more easily able to adapt over time to the demands of being in a parent-like role once again (Hayslip et al., 1998). Relationship quality may be able to override other difficulties that both custodial and traditional grandparents must face, and one way to increase relationship quality is through frequent contact.

There is, however, disagreement in the literature on whether the grandparent role can positively influence grandparent health. Muller and Litwin (2011) oppose this idea; their study examining 3,888 traditional grandparents found that greater grandparent role centrality was related to experiencing more depressive symptoms. Although an important note is that Muller and Litwin (2011) found that participants who only identified with one social role, being a 
grandparent, were the ones who experienced worse psychological wellbeing. However, those who had other social activities in addition to their grandparent role had better psychological health. At the surface, this finding may suggest that grandparent role centrality is harmful and causes depressive symptoms; however, it speaks more to the issues of not having enough social roles leading to poor psychological wellbeing. Grandparents who were engaged in multiple roles had fewer depressive symptoms, while grandparents who were only engaged in a single role had more depressive symptoms (Muller \& Litwin, 2011).

When examining custodial grandparents, however, Hayslip and colleges (1998) found that custodial grandparents with high grandparent role satisfaction had better health than those with low satisfaction. Although, this study did not consider the quantity of other social roles besides grandparent, but they did examine the difficulty of the grandchild. Raising grandchildren can take a toll on older adults but they found with more difficult grandchildren that grandparents are able to eventually adapt over time and can still experience better health (Hayslip et al., 1998). These conflicting findings between custodial and traditional grandparents are why it is imperative that studies be completed with both types of grandparent contexts so that findings are not generalized to under-studied populations. Because of this, our study includes both custodial and traditional grandparents. It is essential to include custodial grandparents in this line of research, because their challenges and experiences may be far from what a traditional grandparent may experience. We know that custodial grandparents face more stress, physical strain, emotional strain, financial tolls, and experience less life satisfaction compared to traditional grandparents (Hayslip et al., 1998). What has not been addressed in the literature yet is whether grandparent role centrality can offset these negative strains of custodial grandparenting and help maintain or protect grandparent psychological wellbeing. 


\section{Current Study}

In order to better understand the experience of grandparents and to better support custodial grandparents, a closer examination of social role centrality is needed. The grandparent role has unique influences on wellbeing, which may vary depending on custodial status. There are currently few studies that directly compare these two populations. Our study seeks to fill that gap in the literature. First, we hypothesize that physical health will have an effect on depressive symptoms experienced by both traditional and custodial grandparents, based on the reciprocal relationship between physical and mental health (Moussavi et al., 2007; Ohrnberger et al., 2017). Secondly, based on the social role theory (George, 1990; Krause, 1994) and previous findings (Hayslip et al., 1998), we hypothesized that higher grandparent role centrality would be associated with less depressive symptoms even with poor physical health than those with low role centrality. Further, we anticipated that the magnitude of effects of grandparent role centrality on the effects of physical health on depressive symptoms would be moderated by the frequency of activities with grandchildren. We additionally proposed that these associations would differ based on custodial status. Thus, we hypothesized that grandparents with high grandparent role centrality who are also highly active with grandchildren would experience less effect of physical health on depressive symptoms stemming from poor physical health. These hypotheses are depicted in Figure 1. Finally, we examined whether the model differs as a function of custodial status since we know that traditional and custodial grandparents experience divergent interactions and involvement with grandchildren. We will investigate model path differences between traditional grandparents and custodial grandparents.

\section{Methods}

\section{Participants}


The current study uses existing data that received funding from The West Virginia Injury Prevention Center and the Eberly College. Participants were recruited within West Virginia using targeted mailing lists and nation-wide using internet-hosted ads approved by the Institutional Review Board, and through Syracuse University's Study Response recruitment system (http://studyresponse.syr.edu/studyresponse/sample.htm). Participants completed all measures via Survey Monkey, an online data collection survey hosting service. The current sample includes 247 grandparents $(\mathrm{M}$ age $=66.5, \mathrm{SD}=10.95$, range 42 to 90 years old $), 46.2 \%$ of whom were grandfathers. The large majority were white $(91.5 \%)$, which is consistent with West Virginia demographics. Many were employed full time (37.2\%), while the rest were unemployed or homemakers $(24.7 \%)$, retired (13.4\%), employed part-time (13.0\%), or students (6.9\%). The rest identified as having "other" status for work (4.8\%). See Table 1 for full sample demographic features.

Of those participants, there were one hundred sixty-four custodial grandparents between the ages of 42 and 80 years old $(M=53.0$ years, $S D=10.508), 64.0 \%$ were male, and $87.2 \%$ were white while $4.3 \%$ were black. Most $(56.1 \%)$ were working full time while $24.6 \%$ were retired/unemployed, most were married $(84.3 \%)$, and $93.5 \%$ were currently responsible for raising their grandchildren (with the remaining 6.5\% having done so in the past). Custodial grandparents reported on a grandchild in their care between the ages of 1 and 18 years old $(\mathrm{M}=$ 8.5 years, $\mathrm{SD}=4.25), 50 \%$ were female. Eighty-three traditional grandparents between the ages of 42 and $90(M=67.3$ years, $S D=12.9)$ were eligible for the current study. All were white, and $89.2 \%$ were female. Most (62.6\%) were retired/unemployed, while only $22.9 \%$ were employed part-time and none reported being full-time employees. Traditional grandparents reported on a 
grandchild between the ages of 1 and $18(M=9.04$ years, $S D=4.455), 49.5 \%$ were female. All grandparents were compensated $\$ 10$ for their participation.

\section{Measures}

Depression. Grandparent depressive symptoms were measured using the Center for Epidemiological Studies-Depression Scale (Radloff, 1977). Participants respond to how frequently they experienced 20 events or feelings within the past week through a 4-category scale, where $0=$ Rarely or None of the Time (Less than 1 Day), $3=$ Most or All of the Time (5-7 Days). Higher scores indicate more depressive symptoms experienced in the past week. For adults, scores of 16 and higher are referred for clinical assessment, and scores above twelve are important sub-threshold levels of symptoms (Hybels, Blazer, \& Pieper, 2001). This measure is moderately correlated to other depression scales ( $r=.44$ to .54$)$, such as the Raskin Rating scale and the Hamilton Clinician's Rating scale (Radloff, 1977). In the current sample, a mean of $14.45(\mathrm{SD}=10.95)$, alpha $=.91$ was obtained. As shown in Table 2, traditional grandparents had a mean of $10.78(\mathrm{SD}=10.43)$ and custodial grandparents had a mean of $16.31(\mathrm{SD}=10.77 ; \mathrm{t}(\mathrm{DF}$ $=245)=-3.85, \mathrm{p}<.001)$.

Health. Grandparent health was measured using a subscale of physical health from the Multilevel Assessment Inventory (Lawton, Moss, Fulcomer, \& Kleban, 1982). The self-report measure asked participants to rate their health in four ways: in general, compared to one year ago, compared to three years prior, and how their health compares to others their age. The scale ranges from four to thirteen, with higher scores representing perceived better health. In the current sample, a mean of $8.98(\mathrm{SD}=2.1)$ alpha .72 was obtained. Note, although the internal consistency is below .8, it is acceptable for a multidimensional index and consistent with other reports of this measure (e.g., Lawton et al., 1982 \& Nadorff \& Patrick, 2018). As shown in Table 
2, traditional grandparents had a mean of $9.37(\mathrm{SD}=1.96)$ and custodial grandparents had a mean of $8.79(\mathrm{SD}=2.09 ; \mathrm{t}(\mathrm{DF}=245)=2.13, \mathrm{p}=.034)$.

Role Centrality. Grandparent role centrality was measured using the Grandparent Role Centrality Scale (Hayslip, Henderson, \& Shore, 2003). The self-report measure asked participants to assess grandparental meaning on 34 questions about role centrality (e.g. I like to see my grandchild more than anything I can think of). Responses were summed, with a higher score indicating a stronger grandparent role centrality. As shown in Table 2, traditional grandparents had a mean factor score for role centrality of $1.09(\mathrm{SD}=0.66)$ and custodial grandparents had a mean factor score of $-0.55(\mathrm{SD}=0.42 ; \mathrm{t}(\mathrm{DF}=245)=23.52, \mathrm{p}<.001)$.

Activities. Grandparent participation in activities with their grandchildren was measured through self-report on the frequency in which they engage in twelve activities with their grandchild (e.g., go shopping together, read together). Activities were adapted from previous research collecting information from grandchildren's perspectives of activities with their grandparents (Ozturk, M. S. \& Hazer, O., 2017; Wiscott \& Kopera-Frye, 2000). Participants responded using a 5-point Likert scale reporting how many times they participated in the activity in the past six months $(1=$ Never, $5=$ More than 10 times $)$. Because the activities scale was novel, we investigated the underlying factor structure of the 12 items using a principal components analysis with Promax rotation, which would allow for correlated factors. A 2-factor solution was obtained, which accounted for $72.04 \%$ of the variance. However, 11 of 12 items loaded onto a single factor $(62.8 \%)$, which we used. The item relating to talking on the computer together did not load onto the used factor. As shown in Table 2, traditional grandparents had a mean factor score of $-0.38(\mathrm{SD}=1.10)$ and custodial grandparents had a mean factor score of $0.19(\mathrm{SD}=0.80 ; \mathrm{t}(\mathrm{DF}=245)=-4.65, \mathrm{p}<.001)$ 


\section{Analyses}

\section{Preliminary Analyses}

Scales were computed using mean-item imputation if participants answered at least $75 \%$ of the items comprising the scale; if fewer than $75 \%$ of the items were present the case was deleted. There were 180 custodial grandparents, 164 with complete data to be used in our study. There were 175 traditional grandparents, 83 with complete data to be used in our study. Fewer than $10 \%$ of the custodial grandparents $(8.8 \%)$ failed to supply sufficient data. Among the traditional grandparents, data from 92 adults were lost due to an administrative error in setting up the survey in which traditional grandparents failed to receive the Grandparent Role Centrality Scale. Table 4 displays the correlations among age, gender, depression, physical health, role centrality, and activities with grandchildren for both traditional and custodial grandparents.

\section{Hypothesis Testing: All Grandparents.}

AMOS was used to test the model shown in Figure 1. To test the hypothesis that central grandparent role moderates the relationship between physical health and depressive symptomatology, and that shared activities further moderate the relation of a central grandparent role, a path model was tested through AMOS 26. As is customary for moderated regression (see Hayes, 2016), the variables were centered and the interaction terms were created. Finally, covariances among the variables were imposed.

We used maximum likelihood estimation to fit the model to the data. A chi-square test is used to assess model fit, with a non-significant $X^{2}$ indicating a close fit of the model to the data. In samples larger than 200, additional fit indices are used, including the root mean square error of approximation (RMSEA), which values less than .08 indicate a good fit; the Tucker-Lewis Index (TLI), which values greater than .90 indicate good fit; and the minimum discrepancy per 
degree of freedom (CMIN/DF), which values less than 5.0 are acceptable (Byrne, 2001; Hayes, 2016). In addition to testing the fit of the overall model, each path in Figure 2 was also tested for significance using the standardized beta and the critical ratio (CR). Like Z-scores, for CR > 1.96, are significant at $\mathrm{p}<.05$ and $\mathrm{CR}>2.16$, are significant at $\mathrm{p}<.01$ (Byrne, 2001).

The results of the model testing for the full sample are shown in Table 3. The chi-squared suggested a poor fit of the model to the data, $X^{2}(\mathrm{DF}=12, \mathrm{~N}=247)=39.15, \mathrm{p}<.001 ; \mathrm{R}^{2}=.236$. However, with samples larger than $\mathrm{N}=200$, additional fit indices are often useful. Therefore, we examined the CMIN/DF, which was an acceptable value of 3.26. We also relied on the TLI= .955 and the RMSEA $=.068$, which also indicated acceptable fit. Inspection of the individual regression paths showed that among the full sample, significant main effects for Role Centrality $(\beta=.699 * * *)$ and Activities $(\beta=-.768 * * *)$ on Depression were detected. However, significant main effects for Subjective Health $(\beta=-.034)$ did not emerge. All two-variable interactions were significant in predicting depression: Role Centrality and Subjective Health $(\beta=-.919 * * *)$, Role Centrality and Activities $\left(\beta=1.153^{* * *}\right)$, and Subjective Health and Activities $(\beta=.690 * * *)$. The three-way interaction term Subjective Health, Role Centrality, and Activities $(\beta=-$ $1.062 * * *)$ was also significant.

Multiple covariances between variables were significant (See Table 4). Subjective Health was correlated with multiple variables: Role Centrality $(\beta=.169 * *)$, Role Centrality and Subjective Health term $\left(\beta=.146^{* *}\right)$. Role Centrality was correlated with Role Centrality and Subjective Health term $\left(\beta=.964^{* * *}\right)$. Activities was correlated with Role Centrality and Activities term $(\beta=.242 * * *)$, Subjective Health and Activities term $(\beta=.953 * * *)$. Role Centrality and Activities term was correlated with the Subjective Health and Activities term $(\beta=$ $.262 * * *)$. There were significant covariances with the three-way interaction term of Subjective 
Health, Role Centrality, and Activities: Subjective Health $(\beta=-.090 * * *)$, Activities $(\beta=$ $.259 * * *)$, Role Centrality and Activities term $(\beta=.947 * * *)$, and the Subjective Health and Activities term $(\beta=.303 * * *)$ were all significantly correlated with the three-way interaction term.

\section{Multigroup Analyses}

After examining the model for the full sample, the model depicted in Figure 2 was tested using multigroup analyses implemented in AMOS. The model accounted for $25.7 \%$ of depression among traditional grandparents. As shown in Table 5, no individual regression paths emerged as significant. Moreover, no interaction terms emerged as significant. As in the full model, multiple covariances were significant for traditional grandparents, as shown in Table 5. It is important to note, however, that our traditional sample is underpowered. These findings may change and possibly become significant if we are able to increase our sample size in the future.

In contrast, however, the model accounted for $36.8 \%$ of depression among custodial grandparents. Table 6 presents regression paths for the custodial grandparents. As shown, each path emerged as statistically significant. Significant effects on Depression from Subjective Health $\left(\beta=.439^{* * *}\right)$, with main effects for Role Centrality $\left(\beta=-.635^{* *}\right)$ and Activities $(\beta=-$ $\left..711^{* *}\right)$ emerged for custodial. Each interaction term also emerged as significant: Role Centrality and Subjective Health term $\left(\beta=.545^{* *}\right)$, Role Centrality and Activities term $\left(\beta=.636^{* *}\right)$, and the Subjective Health and Activities term $\left(\beta=.600^{* *}\right)$, with the 3-way interaction accounting for additional variance in depression $\left(\beta=-.445^{*}\right)$.

Multiple covariances between variables were significant (See Table 6). Subjective Health was correlated with two variables: Role Centrality $\left(\beta=.196^{*}\right)$ and the Role Centrality and Subjective Health term $(\beta=-.180 *)$. Role Centrality was correlated with the Role Centrality and 
Subjective Health term $\left(\beta=.885^{* * *}\right)$. Activities were correlated with two variables: Role Centrality and Activities term $(\beta=-.649 * * *)$ and the Subjective Health and Activities term $(\beta=$ $.943 * * *)$. Role Centrality and Activities term was correlated with Subjective Health and Activities term $(\beta=-.523 * * *)$. Role Centrality and Subjective Health term was correlated with the Subjective Health and Activities term $(\beta=-.074 * * *)$. There were significant covariances with the three-way interaction term of Subjective Health, Role Centrality, and Activities: Subjective Health $\left(\beta=-.106^{* * *}\right)$, Activities $(\beta=-.564 * * *)$, Subjective Health and Activities term $\left(\beta=-.508^{* * *}\right)$, and the Role Centrality and Activities term $(\beta=.935 * * *)$.

Although traditional grandparent analyses were underpowered, we can still examine the direction and magnitude of effects compared to the better powered custodial grandparents. All but two pathways are different directions comparing traditional and custodial betas. Both traditional and custodial grandparents have positive beta weights for the interaction of Role Centrality and Activities on Depression (traditional $\beta=.788$, custodial $\beta=.636^{* *}$ ). They also both have negative beta weights for the three-way interaction term of Subjective Health, Role Centrality, and Activities (traditional $\beta=-.846$, custodial $\beta=-.445^{*}$ ). The rest of the pathways are the opposite direction for traditional and custodial grandparents, including all main effects.

\section{Discussion}

Previous studies have shown that poor physical health is linked to depression (Goldberg, 2010; Moussavi et al., 2007; Ohrnberger et al., 2017). A more sophisticated question is for whom physical health is linked to mental health, also are there ways in which one can mitigate the effect of physical health on depression. Our study set out to explore more refined relations between physical and emotional health, also known as wellbeing (Lawton et al., 1982). One way to contribute to healthy wellbeing is through fulfilling expectations based on a social role, the 
more central the role is to one's identity the more influential the role is on one's wellbeing (Drew \& Silverstein, 2004; George, 1990; Thoits, 1991). A salient and central social role for older adults is being a grandparent (Krause, 1994). Our study set out to examine if the grandparent social role could be utilized to improve older adult wellbeing.

Our predicted conceptual model (see Figure 1) of physical health predicting depression while being moderated by role centrality and activities with grandchildren was supported for custodial grandparents. However, this original model was somewhat accurate when all grandparents were analyzed together but was not supported for traditional grandparents.

When both custodial and traditional grandparents were analyzed together subjective physical health did not directly predict depressive symptomology. All other paths were significant in predicting depression, including the three-way interaction term of health, role centrality, and activities accounting for depression. Grandparent role centrality and shared activities with grandchildren significantly contributed to depression scores. Physical health predicting mental health (depression) did not turn out significant for the full sample of grandparents, this does not align with multiple previous studies (Goldberg, 2010; Moussavi et al., 2007). Possibly, we could still see this link if additional mental health measures were included (e.g. anxiety, general stress, cognitive function). Another reason why we may not have captured this link between physical health and depression is that our sample had extremely high Center for Epidemiological Studies-Depression Scale scores. A full $44 \%$ of our grandparents are above the clinical-referral cutoff. This might be from an interview effect, which has been seen in previous work for older women (Pruchno \& Hayden, 2000). These high depression scores could have impacted the analysis examining the link between physical health and depression for our sample. 
We continued on to separate out custodial and traditional grandparents to see if this model would still hold up when examined in different contexts. For traditional grandparents no paths were significant; the main effects of our predictor variables (physical health, grandparent role centrality, activities with grandchildren) and the interactions did not predict depression. This non-significant finding could be due to there being many different approaches to be a traditional grandparent. Possibly we were not able to capture this diversity with our novel measure examining shared activities with grandchildren. This is interesting because traditional grandparents had higher grandparent role centrality than custodial grandparents, and yet we do not see role centrality influencing one's depression for traditional grandparents. However, our traditional sample was underpowered, so it is difficult to say that no significant path really is a lack of significance. What is interesting that we can pull from this data is that traditional grandparents, although not significant here, had different directions and magnitude of effects compared to custodial grandparents. Possibly our model and hypothesis works in one direction for custodial grandparents and in another direction for traditional grandparents. The traditional grandparent direction of effects seems to point towards previous work which found that having high grandparent role centrality for traditional was linked to increased depression, especially so for grandparents with no other social roles (Muller \& Litwin, 2011). For future studies, it may be important to differentiate traditional grandparents who have few social roles, and those who believe they have multiple roles they act on and draw identity from.

For custodial grandparents, all paths were significant; the main effects of physical health, grandparent role centrality, activities with grandchildren, and all the interactions predicted depression. Our model of one's physical health effects on depression being moderated by 
grandparent role centrality and activities with grandchildren comes out as completely significant for custodial grandparents.

The discrepancy between the outcomes for traditional and custodial grandparents speak to the importance of examining differences between seemingly similar populations. Although custodial and traditional grandparents are all grandparents and have many of the same demographic features, their contexts can be extremely diverse and this needs to be accounted for in analyses. If we had chosen to analyze the whole grandparent sample without reviewing differences based on custodial status, we would have overlooked these peculiar relationships and falsely assumed that our model works for traditional grandparents when really custodial grandparents are the ones driving the significance. Even if one may assume there is only a small degree of difference between the members of a target sample, researchers should still be questioning and examining whether those are true nuances or are significant differences.

Although this work is innovative for this field, there are limitations. First, by using a novel measure we do not have previous work to show its reliability. Although the activities measure we adapted was able to capture enough information for custodial grandparents, additional items are needed to capture all of the likely activities a traditional grandparent may participate in with a grandchild. The novel scale could be adapted to focus on activites with grandchildren that are outside of traditional childcare activites (e.g. eating together), such as adding more items which relate to shared activities all grandparents are equally likely to partake in (e.g. played indoors together). This alteration will be more inclusive of the activites that traditional, and custodial, grandparents share with grandchildren.

Our study can be expanded by including the examination of the relationship quality between grandparents and grandchildren. Previous work has shown that relationship quality is an 
important predictor of grandparent wellbeing (Mahne \& Huxhold, 2015). This could help improve the model and capture a more detailed picture of the context for grandparents. Additionally, in the future, we would want to know more information regarding custodial grandparents' social context. Collecting information on whether parents are present/influential, how one became the guardian of grandchildren, and how much social support custodial grandparents feel they can access, may be additionally significant predictors of wellbeing. 


\section{References}

Byrne, B. M. (2001). Multivariate applications book series. Structural equation modeling with AMOS: Basic concepts, applications, and programming. Lawrence Erlbaum Associates Publishers. Mahwah, N.J.

Carstensen, L. (1995). Evidence for a life-span theory of socioemotional selectivity. Current Directions in Psychological Science, 4, 151-156.

Drew, L. M. \& Silverstein, M. (2004). Inter-generational role investments of great-grandparents: consequences for psychological well-being. Aging and Society, 24, 95-111.

Diener, E. (1984). Subjective well-being. Psychological Bulletin, 95, 542-575.

George, L. K. (1990) Social structure, social processes, and social-psychological states. In R. H. Binstock \& L. K. George (Eds.), The handbook of aging and the social sciences (3rd ed.; pp. 186 - 204). Orlando, FL: Academic Press.

Glaser, K., Stuchbury, R., Price, D., Gessa, G. Di, Ribe, E., \& Tinker, A. (2018). Trends in the prevalence of grandparents living with grandchild(ren) in selected European countries and the United States. European Journal of Ageing, 15, 237-250. https://doi.org/10.1007/s10433-018-0474-3

Goldberg, D. (2010). The detection and treatment of depression in the physically ill. World Psychiatry, 9, 16-20.

Hayes, A. F. (2016). Introduction to mediation, moderation, and conditional process analysis: A regression-based approach ( $2^{\text {nd }}$ Ed.). Guilford Publications.

Hayslip, B. J., Henderson, C. E., \& Shore, R. J. (2003). The Structure of Grandparental Role 
Meaning. Journal of Adult Development, 10(1), 1-11.

Hayslip, B. J., Temple, J. R., Shore, R. J., \& Henderson, C. E. (2006). Determinants of Role Satisfaction Among Traditional and Custodial Grandparents. In B. J. Hayslip \& J. H. Patrick (Eds.), Custodial Grandparenting: Individual, Cultural, and Ethnic Diversity (pp. 21-35). Springer Publishing Company.

Hayslip, B. J., Shore, R. J., Henderson, C. E., \& Lambert, P. L. (1998). Custodial grandparenting and the impact of grandchildren with problems on role satisfaction and role meaning. Journals of Gerontology - Series B Psychological Sciences and Social Sciences, 53(3), 164173. https://doi.org/10.1093/geronb/53B.3.S164

Hybels, C. F., Blazer, D. G., \& Pieper, C. F. (2001). Toward a threshold for subthreshold depression: an analysis of correlates of depression by severity of symptoms using data from an elderly community sample. The Gerontologist, 41(3), 357-365.

Krause, N. (1994). Stressors in salient social roles and wellbeing in later life. Journal of Gerontology: Psychological Sciences, 49B, 137-148.

Lawton M. P., Moss M., Fulcomer M., \& Kleban M. H. (1982). A research and service-oriented Multilevel Assessment Instrument. Journal of Gerontology, 37, 91-99.

Lin, E. H., Katon, W., Von Korff, M., Tang, L., Williams, J. W., Kroenke, K., Hunkeler, E., Harpole, L., Hegel, M., Arean, P., Hoffing, M., Penna, R. D., Langston, C., \& Unützer, J. (2003). Effect of improving depression care on pain and functional outcomes among older adults with arthritis: a randomized controlled trial. The Journal of the American Medical Association, 290, 2428-29. 
Mahne, K., \& Huxhold, O. (2015). Grandparenthood and subjective well-being: Moderating effects of educational level. Journals of Gerontology - Series B Psychological Sciences and Social Sciences, 70(5), 782-792. https://doi.org/10.1093/geronb/gbu147

Marello, M. \& Patrick, J. (2018, November). May You Live to See Your Children's Children: Role Centrality and Shared Activities Reduce Grandparent Depression. Poster session presented at the Annual Scientific Meeting of the Gerontological Society of America, Boston, MA.

Moussavi, S., Chatterji, S., Verdes, E., Tandon, A., Patel, V., \& Ustun, B. (2007). Depression, chronic diseases, and decrements in health: Results from the World Health Surveys. The Lancet, 370, 851-858.

Moy, M. L., Reilly, J. J., Ries, A. L., Mosenifar, Z., Kaplan, R. M., Lew, R., \& Garshick, E. (2009). Multivariate models of determinants of health-related quality of life in severe chronic obstructive pulmonary disease. The Journal of Rehabilitation Research and Development, 46, 643-54.

Muller, Z., \& Litwin, H. (2011). Grandparenting and psychological well-being: How important is grandparent role centrality? European Journal of Ageing, 8(2), 109-118. https://doi.org/10.1007/s10433-011-0185-5

Nadorff, D. K., \& Patrick, J. H. (2018). Predicting child safety: the effect of custodial grandparents' depressive symptoms, home safety, knowledge, and gender. Journal of Intergenerational Relationships, 16(3), 225-242. https://doi.org/10.1080/15350770.2018.1477398

Ohrnberger, J., Fichera, E., \& Sutton, M. (2017). The relationship between physical and mental 
health: A mediation analysis. Social Science \& Medicine, 195, 42-49.

Ozturk, M. S. \& Hazer, O. (2017). The intergenerational activities: Perspectives of young grandchildren. Dumlupinar Universitesi Sosyal Bilimler Dergisi, 53, 55-71.

Patrick, J. H. \& Goedereis, G. A. (2009). The importance of context and the gain-loss dynamic for understanding grandparent caregivers. In K. Shifren (Ed.), How caregiving affects development: Psychological implications for child, adolescent, and adult caregivers (pp. 169-190). American Psychological Association: Washington, DC.

Pittman, L. D., \& Boswell, M. K. (2007). The role of grandmothers in the lives of preschoolers growing up in urban poverty. Applied Developmental Science, 11(1), 20-42. https://doi.org/10.1080/10888690709336721

Poehlmann, J., Park, J., Bouffiou, L., Abrahams, J., Shlafer, R., \& Hahn, E. (2008). Representations of family relationships in children living with custodial grandparents. Attachment and Human Development, 10(2), 165-188. https://doi.org/10.1080/14616730802113695

Pruchno, R. A., \& Hayden, J. M. (2000). Interview modality: Effects on costs and data quality in a sample of older women. Journal of Aging and Health, 12(1), 3-24.

Radloff, L. S. (1977). The CES-D Scale: A Self-Report Depression Scale for Research in the General Population. Applied Psychology Measurement, 1(3), 385-401. https://doi.org/10.1002/ardp.19552881111

Reitzes, D. C., \& Mutran, E. J. (2004). Grandparenthood: Factors Influencing Frequency of grandparent-grandchildren. Journal of Gerontology, 59(1), 9-16. 
Smith, G., \& Palmieri, P. (2007). Risk of Psychological Difficulties Among Children Raised by Custodial Grandparents. Psychiatric Services, 58(10), 1303-1310. https://ps.psychiatryonline.org/doi/pdf/10.1176/ps.2007.58.10.1303

Thoits, P. (1991). On merging identity theory and stress research. Social Psychology Quarterly, $54,101-112$.

Uhlenberg, P., \& Hammill, B. G. (1998). Frequency of Grandparent Contact With Grandchild Sets: Six Factors That Make a Difference, The Gerontologist, 38(3), Pages 276285. https://doi.org/10.1093/geront/38.3.276

Wiscott, R. \& Kopera-Frye, K. (2000). Sharing of culture: Adult grandchildren's perceptions of intergenerational relations. International Journal of Aging and Human Development, 51(3) $199-215$. 


\section{Table 1}

Sample Demographics

\begin{tabular}{lc}
\hline \multicolumn{1}{c}{ Variables } & Sample $(\mathrm{N}=247)$ \\
\hline Age in years & \\
Mean \pm SD & $66.48 \pm 10.95$ \\
Min-Max & $42.0-90.0$
\end{tabular}

Gender

Male (\%)

$114(46.2 \%)$

Female (\%)

$133(53.8 \%)$

Race

White (\%)

$226(91.5 \%)$

African American (\%)

$7(2.8 \%)$

American Indian/Alaska Native (\%)

$2(0.8 \%)$

Hawaiian/Pacific Islander (\%)

$7(2.8 \%)$

Two or more races (\%)

$3(1.2 \%)$

Marital Status

Single $(\%)$

$1(0.4 \%)$

Married (\%)

$168(76.0 \%)$

Widowed (\%)

$31(14.0 \%)$

Divorced (\%)

$21(9.5 \%)$

Current Work Status

Student (\%)

$17(6.9 \%)$

Employed full-time (\%)

$92(37.2 \%)$

Employed part-time (\%)

$32(13.0 \%)$

Retired (\%)

$33(13.4 \%)$

Unemployed/Homemaker (\%)

$61(24.7 \%)$

Other $(\%)$

$9(3.6 \%)$ 


\section{Table 2}

Scale Means, Standard Deviations, and Cronbach's Alpha

\begin{tabular}{|c|c|c|c|c|c|c|c|c|}
\hline \multirow[b]{2}{*}{ Scales } & \multicolumn{3}{|c|}{ Sample } & \multicolumn{2}{|c|}{ Traditional $(\mathrm{N}=83)$} & \multicolumn{2}{|c|}{ Custodial $(\mathrm{N}=164)$} & \multirow{2}{*}{$\begin{array}{c}\mathrm{t} \\
\mathrm{df}=245\end{array}$} \\
\hline & M & SD & $\alpha$ & M & SD & M & $\mathrm{SD}$ & \\
\hline $\begin{array}{l}\text { Center for Epidemiological Studies- } \\
\text { Depression Scale ( } 20 \text { items) }\end{array}$ & 14.45 & 10.95 & .91 & 10.783 & 10.43 & 16.311 & 10.769 & $-3.85^{* *}$ \\
\hline Centered CESD & & & & -0.167 & 10.433 & 5.361 & 10.769 & \\
\hline $\begin{array}{l}\text { Multilevel Assessment Inventory (4 } \\
\text { items) }\end{array}$ & 8.98 & 2.1 & .72 & 9.374 & 1.961 & 8.787 & 2.089 & $2.13^{*}$ \\
\hline Centered MAI & & & & 7.274 & 1.961 & 6.687 & 2.089 & \\
\hline $\begin{array}{l}\text { Grandparent Role Centrality Scale } \\
\text { ( } 25 \text { items) }\end{array}$ & Near 0 & Near 0 & .97 & 1.087 & 0.664 & -.550 & .0423 & $23.52 * *$ \\
\hline $\begin{array}{l}\text { Grandparents Activities with } \\
\text { Grandchild (11 items) }\end{array}$ & Near 0 & Near 0 & .95 & -0.38 & 1.11 & 0.193 & 0.803 & $-4.65 * *$ \\
\hline
\end{tabular}

Note. ${ }^{* *}=\mathrm{p}<.001, *=\mathrm{p}<.05$. Grandparent Role Centrality and Grandparent Activities with Grandchild are mean factor scores. 


\section{Table 3}

Path Analysis for Entire Sample

\begin{tabular}{|c|c|c|c|c|c|}
\hline & $\beta$ & b & $\mathrm{SE}(\mathrm{b})$ & $\mathrm{CR}$ & $p$ \\
\hline \multicolumn{6}{|l|}{ Regression paths } \\
\hline Health $\rightarrow$ Depression & -.034 & -.180 & .321 & -0.574 & .574 \\
\hline Role Centrality $\rightarrow$ Depression & 699 & 8.277 & 2.770 & 2.989 & .003 \\
\hline Activities $\rightarrow$ Depression & -.768 & -8.873 & 2.288 & -3.878 & .000 \\
\hline Health $\mathrm{x}$ Activities $\rightarrow$ Depression & .690 & 1.081 & .315 & 3.434 & .000 \\
\hline Role Centrality x Activities $\rightarrow$ Depression & 1.153 & 14.993 & 2.529 & 5.929 & .000 \\
\hline Role Centrality x Health $\rightarrow$ Depression & -.919 & -1.514 & .381 & -.973 & .000 \\
\hline Health x Role Centrality x Activities $\rightarrow$ Depression & -1.062 & -1.845 & .353 & -5.376 & .000 \\
\hline Covariances & $\beta$ & $\mathrm{b}$ & $\mathrm{SE}(\mathrm{b})$ & $\mathrm{CR}$ & $p$ \\
\hline Health $\leftrightarrow$ Role Centrality & .169 & .322 & .123 & 2.606 & .009 \\
\hline Health $\longleftrightarrow$ Activities & .024 & .048 & .120 & .397 & .691 \\
\hline Activities $\longleftrightarrow$ Role Centrality & -.017 & -.015 & .012 & -1.287 & .198 \\
\hline Health $\longleftrightarrow$ Health x Activities & .004 & .064 & .875 & .073 & .942 \\
\hline Health $\longleftrightarrow$ Health x Role Centrality & .146 & 2.007 & .884 & 2.269 & .023 \\
\hline Activities $\longleftrightarrow$ Activities x Role Centrality & .242 & .194 & .053 & 3.696 & .000 \\
\hline Activities $\longleftrightarrow$ Activities x Health & .953 & 6.353 & .588 & 10.811 & .000 \\
\hline
\end{tabular}


Role Centrality $\longleftrightarrow$ Role Centrality x Health

Health x Activites $\longleftrightarrow$ Health x Role Centrality

Role x Activities $\longleftrightarrow$ Health x Role Centrality

Role x Activities $\longleftrightarrow$ Health x Activities

Health $\longleftrightarrow$ Health x Role Centrality x Activities

Activities $\longleftrightarrow$ Health x Role Centrality x Activities

Role Cent $\longleftrightarrow$ Health x Role Centrality x Activities

Health x Role $\longleftrightarrow$ Health x Role Centrality x Activities

Health x Activity $\longleftrightarrow$ Health x Role Centrality x Activities

Role x Activity $\longleftrightarrow$ Health x Role Centrality x Activities

\begin{tabular}{rrrrr}
$\beta$ & $\mathrm{b}$ & $\mathrm{SE}(\mathrm{b})$ & $\mathrm{CR}$ & $p$ \\
.964 & 5.960 & .548 & 10.877 & .000 \\
-.010 & -.473 & .611 & -0.774 & .439 \\
.025 & 1.550 & .390 & 3.972 & .000 \\
.262 & 1.550 & .390 & 3.972 & .000 \\
-.090 & -1.177 & .277 & -4.256 & .000 \\
.259 & 1.556 & .396 & 3.926 & .000 \\
.020 & .119 & .116 & 1.020 & .308 \\
.019 & .804 & 1.086 & .741 & .459 \\
.303 & 13.451 & 2.956 & 4.551 & .000 \\
.947 & 5.061 & .469 & 10.803 & .000 \\
\hline $.955 ;$ RMSEA $=.068 ; \mathrm{CFI}=.994$ &
\end{tabular}

Note. $X^{2}(\mathrm{DF}=12, N=247)=39.15, \mathrm{p}<.001 ; \mathrm{R}^{2}=.236 . \mathrm{CMIN} / \mathrm{df}=3.263 ; \mathrm{TLI}=.955 ; \mathrm{RMSEA}=.068 ; \mathrm{CFI}=.994$ 


\section{Table 4}

Correlations among variables for traditional $(\mathrm{N}=83)$ and custodial grandparents $(\mathrm{N}=164)$.

\begin{tabular}{lcccccc}
\hline & 1. Age & 2. Gender & 3. Depression & 4. Health & 5. Role & $\begin{array}{l}\text { 6. } \\
\text { Activities }\end{array}$ \\
\hline 1. Age & - & -.020 & -.192 & -.127 & -.051 & -.384 \\
2. Gender & -.020 & - & -.202 & .261 & .540 & .131 \\
3. Depression & -.192 & -.097 & - & .037 & -.181 & -.080 \\
4. Perceived Health & -.127 & .226 & .072 & - & .166 & .004 \\
$\begin{array}{l}\text { 5. Grandparent Role } \\
\text { Centrality }\end{array}$ & -.051 & .252 & .033 & .098 & - & -.183 \\
$\begin{array}{l}\text { 6. Activities with } \\
\text { Grandchildren }\end{array}$ & -.384 & .332 & -.159 & .045 & .102 & -
\end{tabular}

Note. Correlations for traditional grandparents are above the diagonal, correlations for custodial grandparents are below the diagonal. 


\section{Table 5}

Path Analysis for Traditional Grandparents

\begin{tabular}{|c|c|c|c|c|c|}
\hline & $\beta$ & b & $\mathrm{SE}(\mathrm{b})$ & $\mathrm{CR}$ & $p$ \\
\hline \multicolumn{6}{|l|}{ Regression paths } \\
\hline Health $\rightarrow$ Depression & -.306 & -1.602 & 1.128 & -1.420 & .156 \\
\hline Role Centrality $\rightarrow$ Depression & 669 & 10.628 & 7.361 & 1.444 & .149 \\
\hline Activities $\rightarrow$ Depression & .417 & 3.932 & 6.610 & .595 & .552 \\
\hline Health $\mathrm{x}$ Activities $\rightarrow$ Depression & -.357 & -.433 & .866 & -.500 & .617 \\
\hline Role Centrality x Activities $\rightarrow$ Depression & .788 & 6.353 & 5.570 & 1.141 & .254 \\
\hline Role Centrality x Health $\rightarrow$ Depression & -.676 & -1.264 & .983 & -1.286 & .198 \\
\hline Health x Role Centrality x Activities $\rightarrow$ Depression & -.846 & -.871 & .723 & -1.205 & .228 \\
\hline Covariances & $\beta$ & b & $\mathrm{SE}(\mathrm{b})$ & $\mathrm{CR}$ & $p$ \\
\hline Health $\longleftrightarrow$ Role Centrality & .083 & .108 & .131 & .823 & .410 \\
\hline Health $\leftrightarrow$ Activities & -.075 & -.165 & .124 & -1.328 & .184 \\
\hline Activities $\longleftrightarrow$ Role Centrality & .032 & .023 & .017 & 1.351 & .177 \\
\hline Health $\longleftrightarrow$ Health $x$ Activities & -.214 & -3.636 & 1.168 & -3.113 & .002 \\
\hline Health $\longleftrightarrow$ Health x Role Centrality & .440 & 4.858 & 1.258 & 3.860 & .000 \\
\hline Activities $\longleftrightarrow$ Activities x Role Centrality & .753 & 1.074 & .196 & 5.479 & .000 \\
\hline Activities $\longleftrightarrow$ Activities x Health & .957 & 9.071 & 1.420 & 6.386 & .000 \\
\hline
\end{tabular}




\begin{tabular}{|c|c|c|c|c|c|}
\hline Role Centrality $\longleftrightarrow$ Role Centrality x Health & .907 & 3.299 & .531 & 6.217 & .000 \\
\hline Health x Activites $\leftrightarrow$ Health x Role Centrality & -.082 & -3.934 & 1.234 & -3.189 & .001 \\
\hline Role x Activities $\longleftrightarrow$ Health x Role Centrality & -.016 & -.113 & .153 & -.737 & .461 \\
\hline Role $\mathrm{x}$ Activities $\longleftrightarrow$ Health $\mathrm{x}$ Activities & .703 & 7.789 & 1.467 & 5.310 & .000 \\
\hline Health $\leftrightarrow$ Health x Role Centrality x Activities & -.138 & -2.760 & .740 & -3.726 & .000 \\
\hline Activities $\longleftrightarrow$ Health x Role Centrality x Activities & .724 & 8.086 & 1.491 & 5.425 & .000 \\
\hline Role Cent $\longleftrightarrow$ Health x Role Centrality x Activities & -.045 & -.301 & .179 & -1.683 & .092 \\
\hline Health $x$ Role $\longleftrightarrow$ Health $x$ Role Centrality x Activities & -.125 & -7.019 & 2.241 & -3.133 & .002 \\
\hline Health x Activity $\longleftrightarrow$ Health x Role Centrality x Activities & .753 & 65.296 & 11.521 & 5.668 & .000 \\
\hline Role x Activity $\longleftrightarrow$ Health x Role Centrality x Activities & .952 & 12.417 & 1.968 & 6.310 & .000 \\
\hline
\end{tabular}




\section{Table 6}

Path Analysis for Custodial Grandparents

\begin{tabular}{|c|c|c|c|c|c|}
\hline & $\beta$ & $\mathrm{b}$ & $\mathrm{SE}(\mathrm{b})$ & $\mathrm{CR}$ & $p$ \\
\hline \multicolumn{6}{|l|}{ Regression paths } \\
\hline Health $\rightarrow$ Depression & .439 & 2.311 & .552 & 4.188 & .000 \\
\hline Role Centrality $\rightarrow$ Depression & -.635 & -16.496 & 5.706 & -2.891 & .004 \\
\hline Activities $\rightarrow$ Depression & -.711 & -9.642 & 3.858 & -2.499 & .012 \\
\hline Health $\mathrm{x}$ Activities $\rightarrow$ Depression & .600 & 1.128 & .476 & 2.368 & .018 \\
\hline Role Centrality x Activities $\rightarrow$ Depression & .636 & 14.378 & 5.799 & 2.479 & .013 \\
\hline Role Centrality x Health $\rightarrow$ Depression & .545 & 2.017 & .816 & 2.471 & .013 \\
\hline Health x Role Centrality x Activities $\rightarrow$ Depression & -.445 & -1.498 & .755 & -1.984 & .047 \\
\hline Covariances & $\beta$ & $\mathrm{b}$ & $\mathrm{SE}(\mathrm{b})$ & $\mathrm{CR}$ & $p$ \\
\hline Health $\longleftrightarrow$ Role Centrality & .196 & .172 & .070 & 2.475 & .013 \\
\hline Health $\leftrightarrow$ Activities & -.039 & -.066 & .083 & -.794 & .427 \\
\hline Activities $\longleftrightarrow$ Role Centrality & .035 & .012 & .006 & 1.881 & .060 \\
\hline Health $\longleftrightarrow$ Health $x$ Activities & .030 & .360 & 677 & .532 & .595 \\
\hline Health $\longleftrightarrow$ Health x Role Centrality & -.180 & -1.112 & .489 & -2.271 & .023 \\
\hline Activities $\longleftrightarrow$ Activities x Role Centrality & -.649 & -.255 & .037 & -6.967 & .000 \\
\hline Activities $\longleftrightarrow$ Activities x Health & .943 & 4.444 & .501 & 8.873 & .000 \\
\hline
\end{tabular}


Role Centrality $\longleftrightarrow$ Role Centrality x Health

Health x Activites $\longleftrightarrow$ Health x Role Centrality

Role x Activities $\longleftrightarrow$ Health x Role Centrality

Role x Activities $\longleftrightarrow$ Health x Activities

Health $\longleftrightarrow$ Health x Role Centrality x Activities

Activities $\longleftrightarrow$ Health x Role Centrality x Activities

Role Cent $\longleftrightarrow$ Health x Role Centrality x Activities

Health x Role $\longleftrightarrow$ Health x Role Centrality x Activities

Health x Activity $\longleftrightarrow$ Health x Role Centrality x Activities

Role x Activity $\longleftrightarrow$ Health x Role Centrality x Activities

\begin{tabular}{rrrrr}
$\beta$ & $\mathrm{b}$ & $\mathrm{SE}(\mathrm{b})$ & $\mathrm{CR}$ & $p$ \\
.885 & 1.109 & .129 & 8.567 & .000 \\
-.074 & -1.276 & .359 & -3.556 & .000 \\
-.002 & -.002 & .030 & -.078 & .938 \\
-.523 & -1.479 & .249 & -5.931 & .000 \\
-.106 & -.718 & .197 & -3.637 & .000 \\
-.564 & -1.486 & .236 & -6.298 & .000 \\
-.012 & -.017 & .036 & -.466 & .641 \\
.022 & .212 & .340 & .623 & .534 \\
-.508 & -9.656 & 1.657 & -5.827 & .000 \\
.935 & 1.479 & .169 & 8.744 & .000 \\
\hline $.955 ;$ RMSEA $=.068 \cdot \mathrm{CFI}=-994$ &
\end{tabular}

Note. $X^{2}(\mathrm{DF}=12, N=164)=39.15, \mathrm{p}<.001 ; \mathrm{R}^{2}=.368 . \mathrm{CMIN} / \mathrm{df}=3.263 ; \mathrm{TLI}=.955 ; \mathrm{RMSEA}=.068 ; \mathrm{CFI}=.994$ 


\section{Figure 1}

\section{Conceptual Model of a Moderated Moderation}

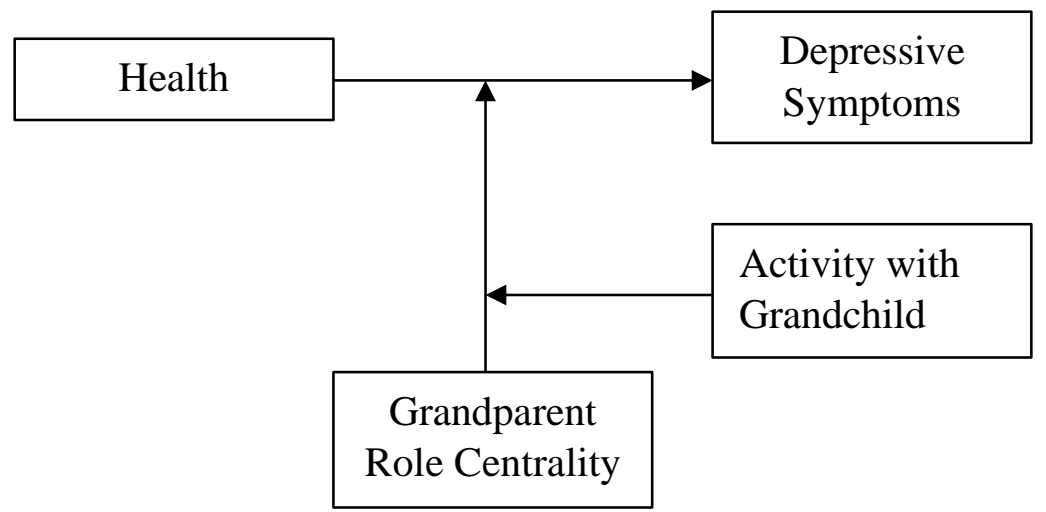

Note. The conceptual model of the study variables and their influence on grandparent depressive symptoms. 


\section{Figure 2}

Tested Pathways for the Moderated Moderation

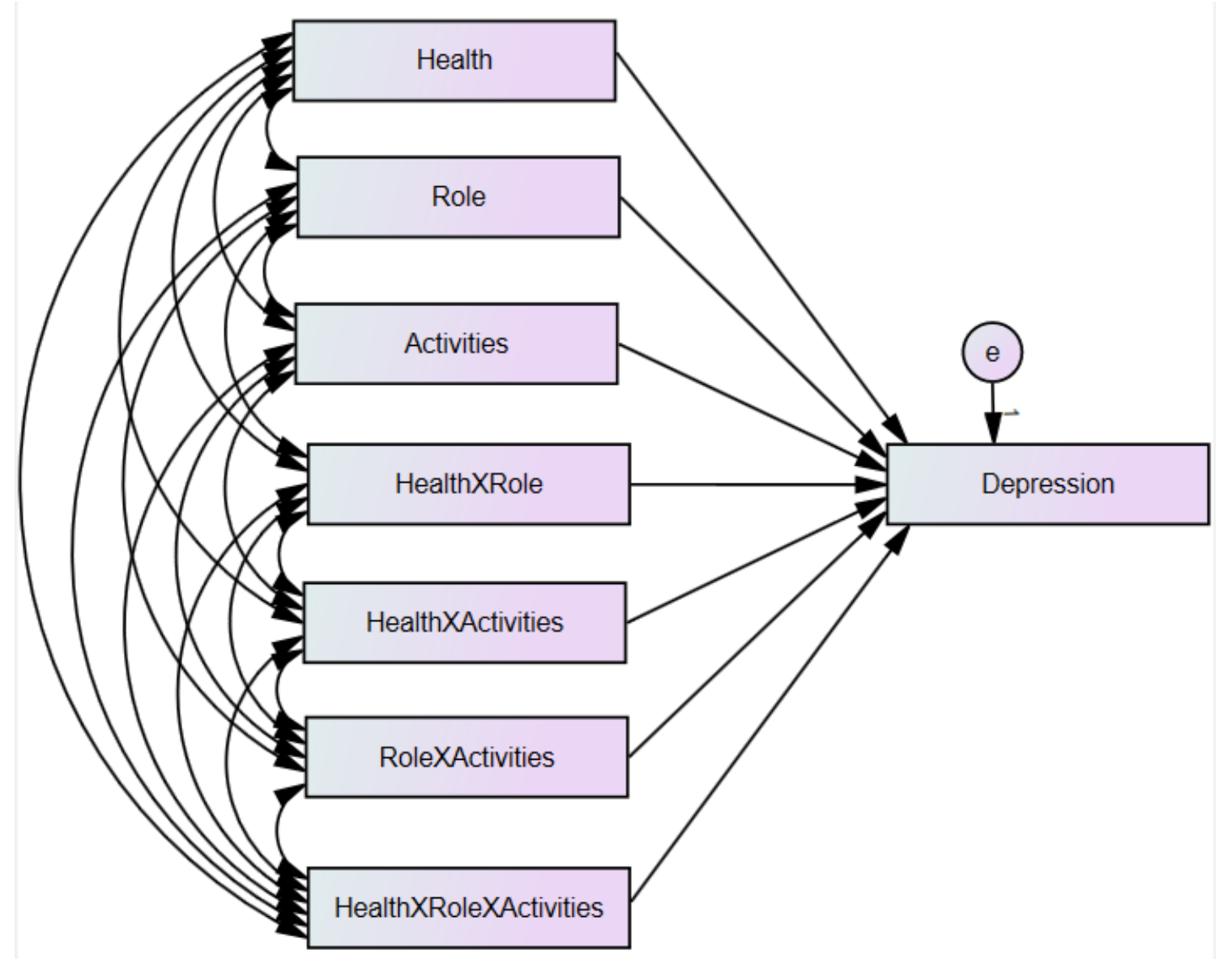




\section{Appendix A}

\section{Number of Grandchildren}

In the current sample, the number of total grandchildren reported varied widely, with a mean of $4.43(\mathrm{SD}=4.3)$, with a range of $0 *$ to 5 grandchildren living in the grandparent's household (* traditional grandparents do not have any grandchildren living in their household). The mean age of the grandchild participants reported on was 8.5 years ( $\mathrm{SD}=4.5$ ), range 1 to 18 years. Of grandchildren reported on, $48.3 \%$ were girls and $51.7 \%$ were boys. For the entire sample, $44 \%$ had no grandchildren currently living in their household, 30\% had one grandchild in their household, $15 \%$ had two in their household, and $11 \%$ had three or more in their household.

In order to examine the potential influence of number of grandchildren, we examined zero-order and partial correlations among the model constructs, controlling for number of grandchildren. The table below presents those correlation coefficients, with the zero-order coefficients above the diagonal and the partial correlation coefficients, controlling for number of grandchildren, shown below. We follow this with a table of r-to-Z transformations. As shown below, partialling out the effects of the number of grandchildren did not alter the magnitude of associations among the model constructs.

Table A1

Correlation Coefficients

\begin{tabular}{llllll}
\hline & CESD & Health & Role Central & Activities & $\begin{array}{l}\text { Number of } \\
\text { GC }\end{array}$ \\
\hline CESD & $\mathbf{1 . 0}$ & $\mathbf{. 0 3 7}$ & $\mathbf{- . 1 8 1}$ & $\mathbf{- . 0 8 0}$ & $\mathbf{- . 2 0 5}$ \\
Health & .075 & 1.0 & $\mathbf{. 1 6 6}$ & $\mathbf{. 0 0 4}$ & $\mathbf{. 1 7 2}$ \\
Role Central & -.148 & .138 & 1.0 & $\mathbf{- . 1 8 3}$ & $\mathbf{. 1 8 9}$ \\
Activities & -.077 & .001 & -.190 & 1.0 & $\mathbf{. 0 2 2}$ \\
\hline
\end{tabular}

Note: Zero-order coefficients are bolded and above the diagonal 


\section{Table A2}

Pearson $r$ to $Z$ table

\begin{tabular}{lrrrl}
\hline Comparison & Zero-order & Partial & Z & significance \\
\hline r(CESD, Health) & .037 & .075 & -.042 & NS \\
rCESD, Role) & -.181 & -.148 & -.037 & NS \\
r(CESD, Activities) & -.080 & -.077 & -.03 & NS \\
\hline
\end{tabular}




\section{Appendix B}

\section{Marital Status}

Most adults in the current sample were married, with only 53 reporting being single, widowed or divorced. Although underpowered to detect differences within the model, we examined the potential influence of being married versus not married by inspecting and testing the zero-order and partial correlations among the model constructs. The table below presents those correlation coefficients, with the zero-order coefficients above the diagonal and the partial correlation coefficients, controlling for married versus not, shown below. We follow this with a table of r-to-Z transformations. As shown below, partialling out the effects of married versus not did alter the magnitude of the association between depression and activities. Future research, with a better distribution of marital status should examine this association.

\section{Table B1}

Correlation Coefficients

\begin{tabular}{llllll}
\hline & CESD & Health & Role Central & Activities & Married/Not \\
\hline CESD & $\mathbf{1 . 0}$ & $\mathbf{. 0 3 7}$ & $\mathbf{- . 1 8 1}$ & $\mathbf{- . 0 8 0}$ & $\mathbf{. 1 8 5}$ \\
Health & .065 & 1.0 & $\mathbf{. 1 6 6}$ & $\mathbf{. 0 0 4}$ & $\mathbf{- . 1 3 8}$ \\
Role Central & -.076 & .098 & 1.0 & $\mathbf{- . 1 8 3}$ & $\mathbf{- . 6 8 4}$ \\
Activities & .119 & .032 & -.073 & 1.0 & $\mathbf{. 1 9 1}$ \\
\hline
\end{tabular}

Note: Zero-order coefficients are bolded and above the diagonal 


\section{Table B2}

Pearson $r$ to $Z$ table

\begin{tabular}{lrrrl}
\hline Comparison & Zero-order & Partial & Z & significance \\
\hline r(CESD, Health) & .037 & .065 & -0.31 & NS \\
rCESD, Role) & -.181 & -.076 & -1.18 & NS \\
r(CESD, Activities) & -.080 & .119 & -2.21 & $\mathrm{p}<.03$ \\
\hline
\end{tabular}




\section{Appendix C}

\section{Paths across groups comparison}

This follow up post hoc shows that the pathways in our model work differently based on custodial status. The direct effects of health on depression and role centrality on depression are significantly different between traditional and custodial grandparents. Additionally, their interaction term of role centrality and health on depression is significantly different.

\section{Table C1}

Group comparison across paths

\begin{tabular}{|c|c|c|c|c|c|c|c|c|}
\hline & & & \multicolumn{2}{|c|}{ Custodial } & \multicolumn{2}{|c|}{ Traditional } & \multirow[b]{2}{*}{ z-score } & \\
\hline & & & Estimate & $\mathrm{P}$ & Estimate & $\mathrm{P}$ & & \\
\hline CESD & $\leftarrow$ & Health & 2.311 & 0.000 & -1.602 & 0.156 & -3.116 & $* * *$ \\
\hline CESD & $\leftarrow$ & Role Central & -16.496 & 0.004 & 10.628 & 0.149 & 2.912 & $* * *$ \\
\hline CESD & $\leftarrow$ & Activities & -9.642 & 0.012 & 3.932 & 0.552 & 1.774 & $*$ \\
\hline CESD & $\leftarrow$ & RoleXHealth & 2.017 & 0.013 & -1.264 & 0.198 & -2.568 & $* *$ \\
\hline CESD & $\leftarrow$ & RoleXActivities & 14.378 & 0.013 & 6.353 & 0.254 & -0.998 & \\
\hline CESD & $\leftarrow$ & HealthXActivities & 1.128 & 0.018 & -0.433 & 0.617 & -1.579 & \\
\hline CESD & $\leftarrow$ & HealthXActivitiesXRole & -1.498 & 0.047 & -0.871 & 0.228 & 0.600 & \\
\hline
\end{tabular}

Notes: $* * *$ p-value $<0.01 ; * *$ p-value $<0.05 ; *$ p-value $<0.10$ 


\section{Appendix D}

Age

Participants mean age was 66.48 years (SD 10.95), with a range of 42 to 90 years. Although underpowered to detect differences within the model, we examined the potential influence of age by inspecting and testing the zero-order and partial correlations among the model constructs. The table below presents those correlation coefficients, with the zero-order coefficients above the diagonal and the partial correlation coefficients, controlling for age, shown below. We follow this with a table of r-to-Z transformations. As shown below, partialling out the effects of age did not alter the magnitude of the association between depression and activities.

\section{Table D1}

Correlation Coefficients

\begin{tabular}{llllll}
\hline & CESD & Health & Role Central & Activities & Age \\
\hline CESD & $\mathbf{1 . 0}$ & $\mathbf{- . 3 8 6}$ & $\mathbf{. 1 1 4}$ & $\mathbf{. 0 6 2}$ & $\mathbf{- . 1 9 2}$ \\
Health & -.422 & 1.0 & $\mathbf{- . 0 2 0}$ & $\mathbf{. 1 0 1}$ & $\mathbf{- . 1 2 7}$ \\
Role Central & .106 & -.027 & 1.0 & $\mathbf{. 3 0 5}$ & $\mathbf{- . 0 5 1}$ \\
Activities & -.012 & .057 & .309 & 1.0 & $\mathbf{- . 3 8 4}$ \\
\hline
\end{tabular}

Note: Zero-order coefficients are bolded and above the diagonal 


\section{Table D2}

Pearson $r$ to $Z$ table

\begin{tabular}{lrrrl}
\hline Comparison & Zero-order & Partial & Z & significance \\
\hline r(CESD, Health) & -.386 & -.442 & 0.75 & NS \\
rCESD, Role) & .114 & .106 & 0.09 & NS \\
r(CESD, Activities) & .062 & -.012 & 0.82 & NS \\
\hline
\end{tabular}




\section{Appendix E}

\section{Graphed Simple Slopes}

Examination of the interaction plot showed different effects for custodial and traditional grandparents for the independent variables of physical health, role centrality, activites with grandchildren and the dependent variable depression. For custodial grandparents with low physical health, there is a beneficial effect as role centrality and activities with grandchildren increased, depression was lower. At high physical health, depression was similar for high or low role centrality and activites with grandchildren. As hypothesized, low physical health custodial grandparents with high role centrality and enacting by activites with grandchild have a moderating effect and their depression is lower. Additionally, even custodial grandparents who have low role centrality but share activites with grandchildren still have lower depression than those who do not engage with grandchildren. For traditional grandparents, there seems to be the opposite effect of activites with grandchildren. Those with poor health that engage with grandchildren have more depression symptomology than those who have less shared activities.

\section{Table E1}

\section{Custodial Grandparents Simple Slopes}

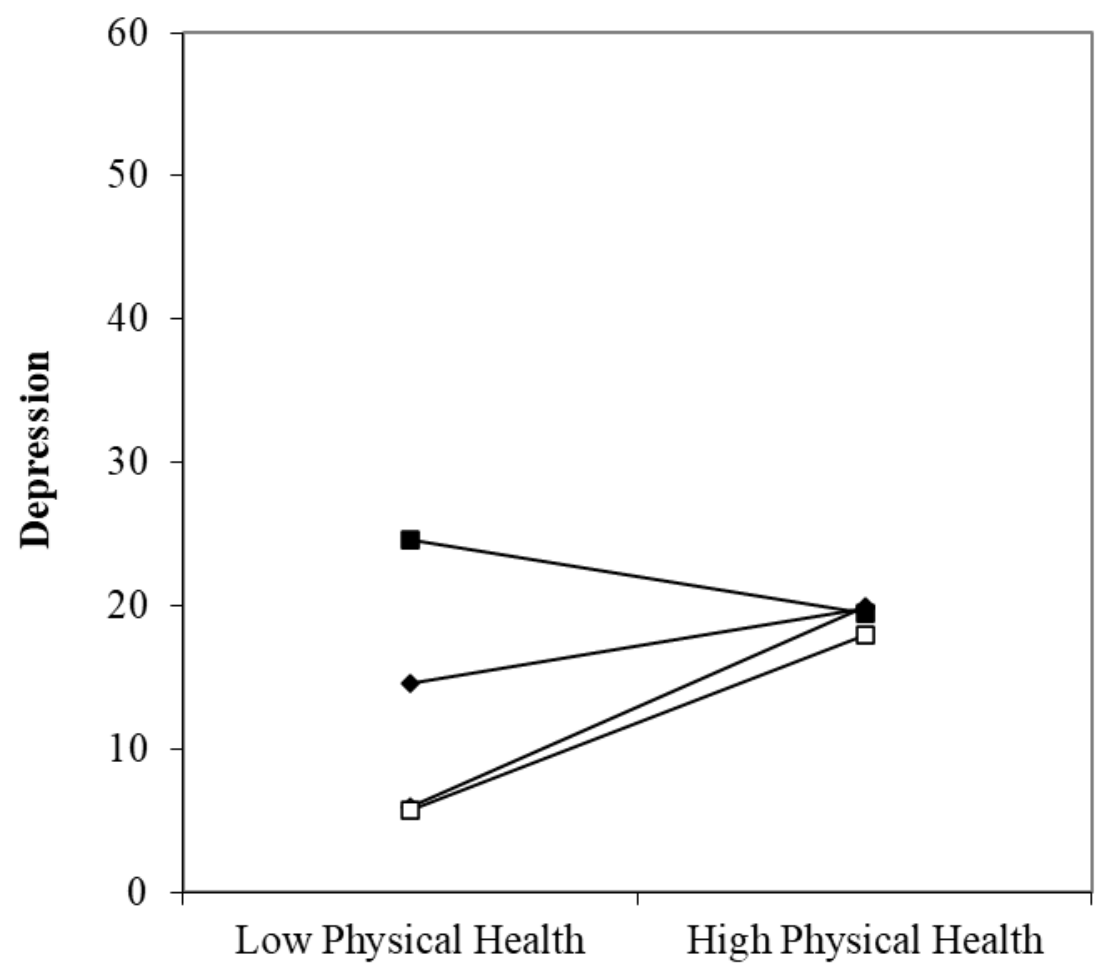

$\sim$ (1) High Role Centrality, High Activities

$\neg$ (2) High Role Centrality, Low Activities

$\rightarrow \square-(3)$ Low Role Centrality, High Activities

$\rightarrow-(4)$ Low Role Centrality, Low Activities 


\section{Table E2}

Traditional Grandparents Simple Slopes

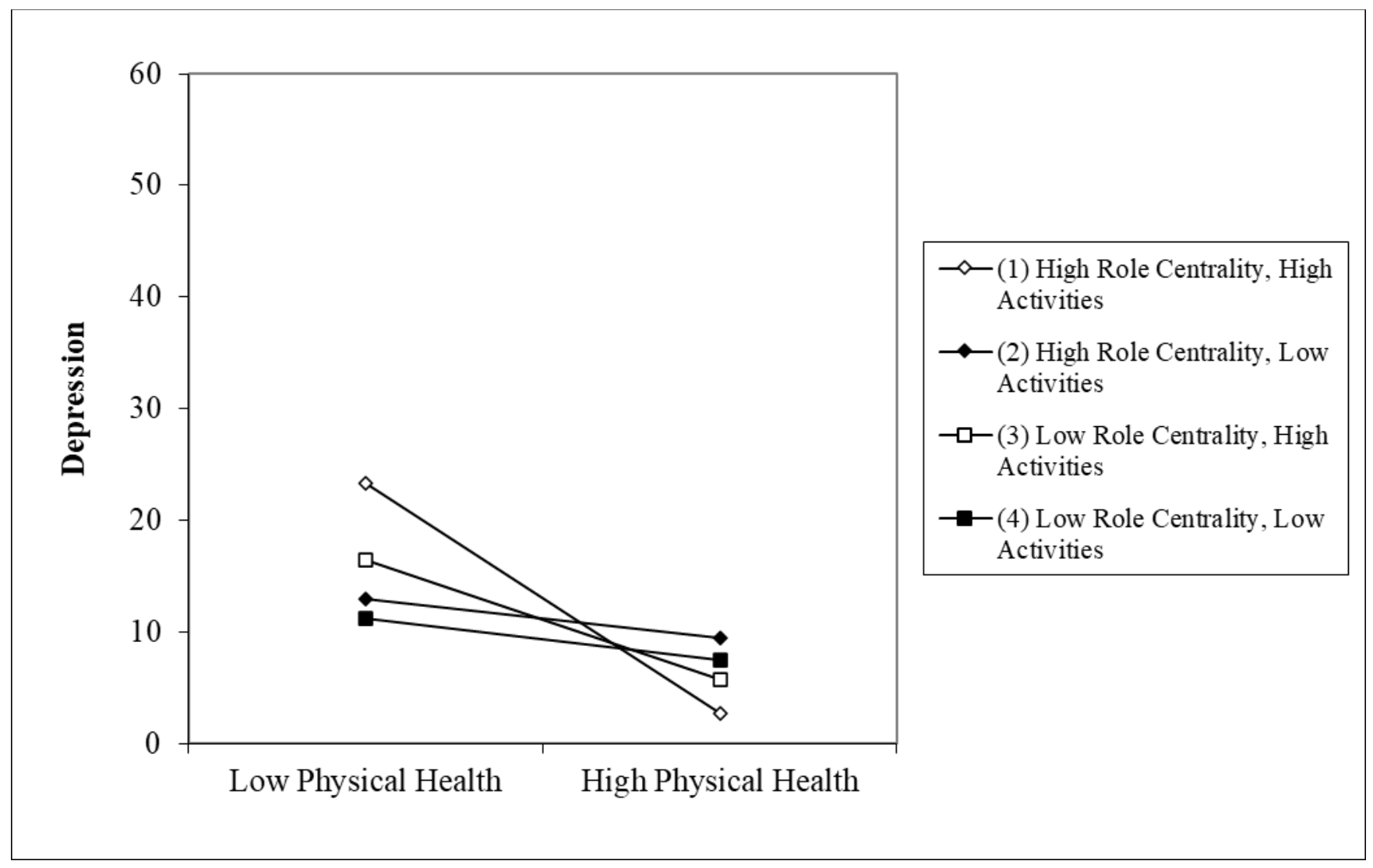




\section{Appendix F}

\section{Survey Format}

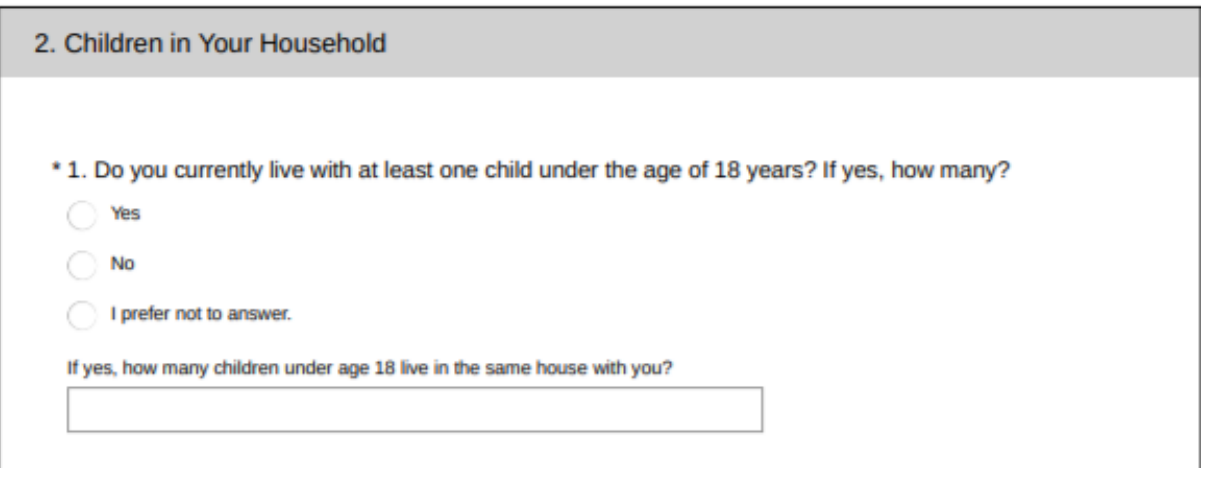

3. Children in Your Household (continued)

-1. Are all of the children younger than age 18 with whom you live your children or your step-children?

Yes

No

1 prefer not to answer.

-2. Are all of the children younger than age 18 with whom you live your grandchildren or step-grandchildren?

Yes

No

1 prefer not to answer.

-3. Do you live with both your own child/step-child younger than age 18 AND at least one grandchild/step grandchild younger than age 18 ?

Yes

No

I prefer not to answer.

Please tell us how many of each of these live with you: Children, step-children, grandchildren, and step-grandchildren.

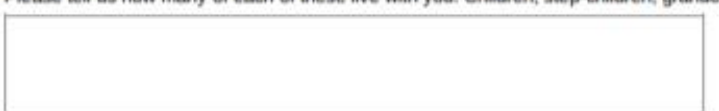

-4. Is the child younger than 18 who lives with you neither your child nor your grandchild?

Yes, the child is neither my child nor my grandchild.

No, the child is either my child or grandchild.

I prefer not to answer.

Please specily the relationship(s) of any children in your home who are neither your child nor your grandchild (e.g., nephew, foster child, etc.)

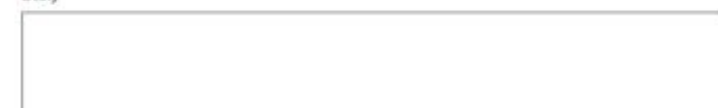




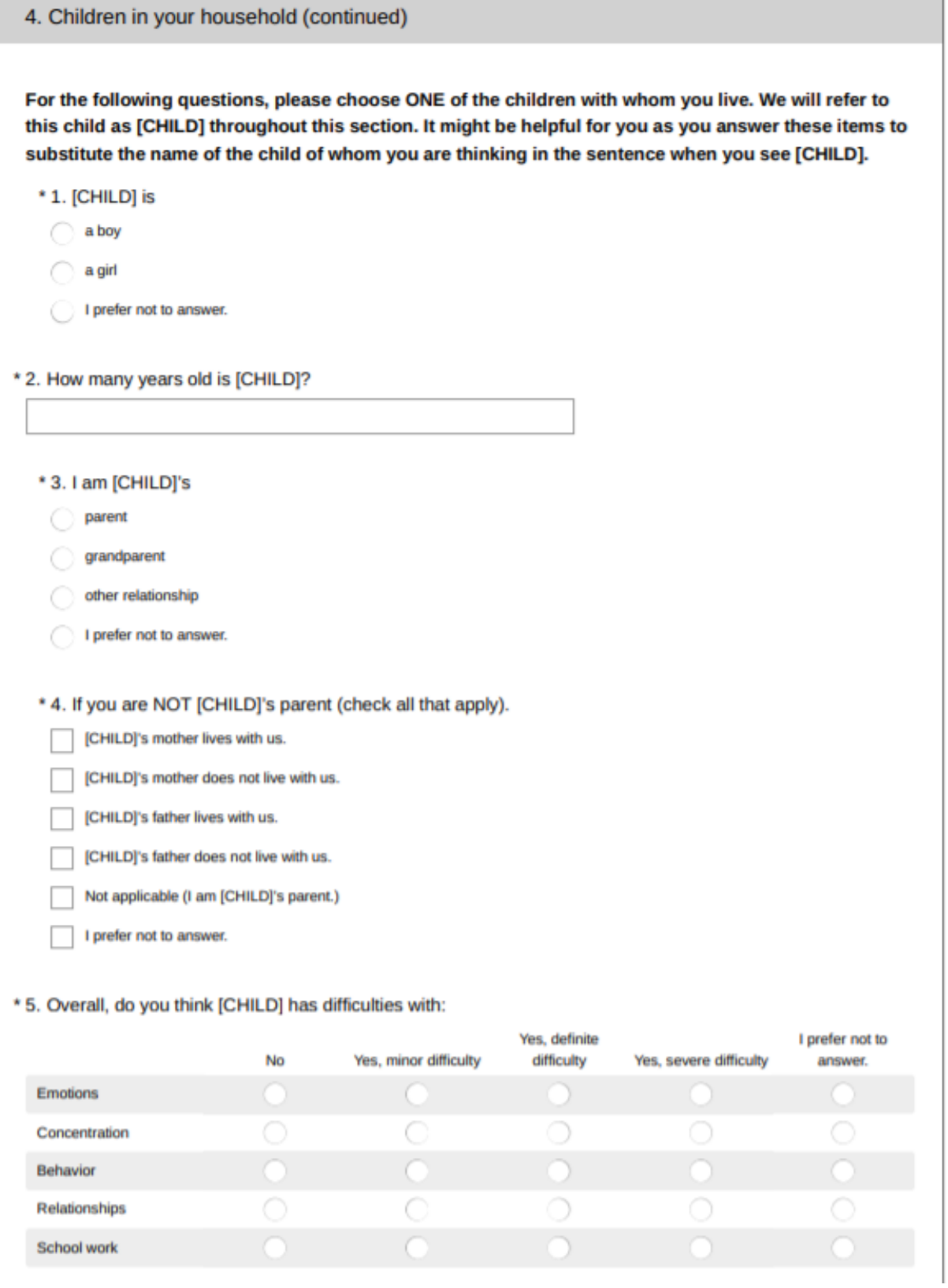

*5. Overall, do you think [CHILD] has difficulties with:

Emotions
Concentration
Behavior
Relationships
School work




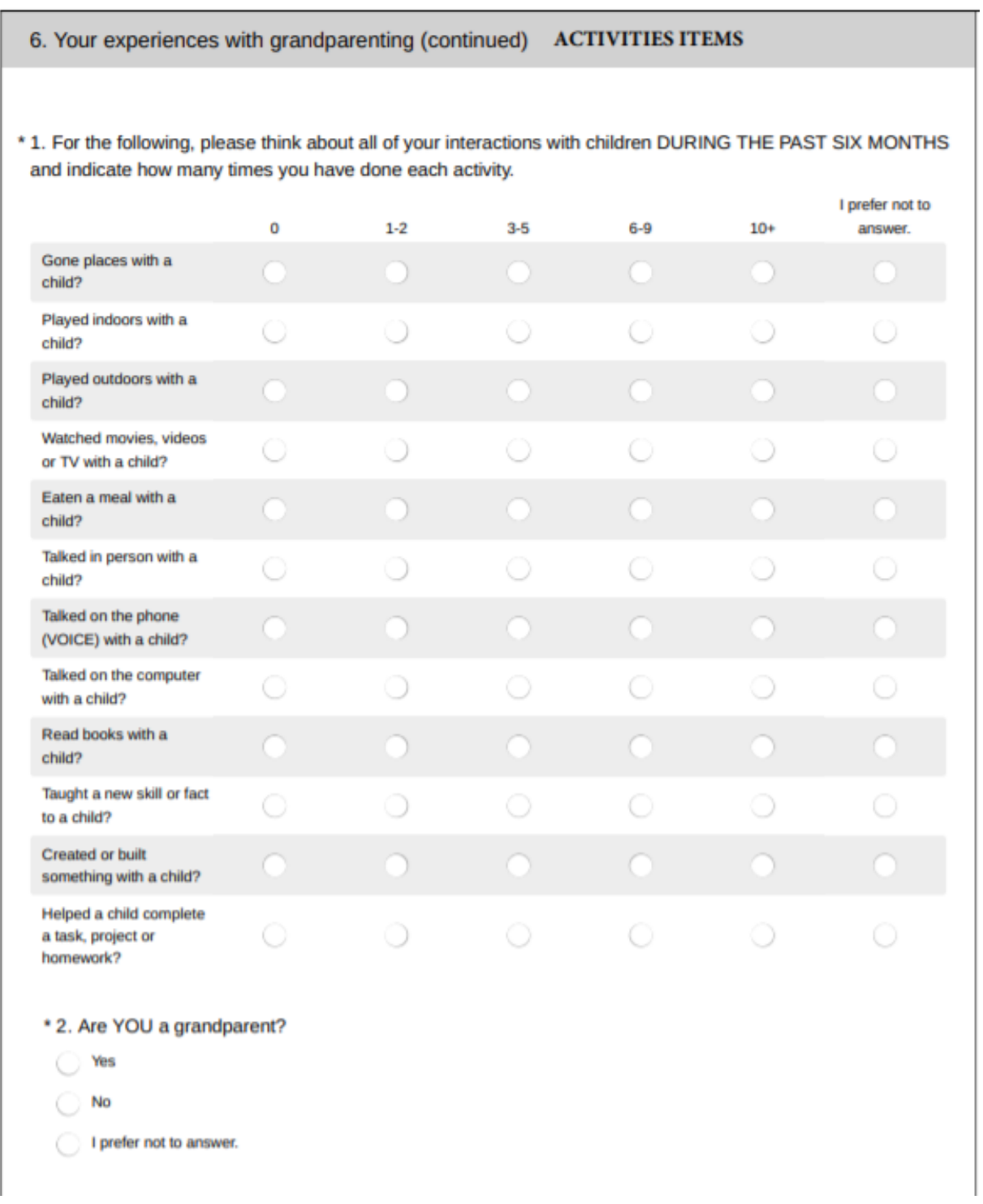




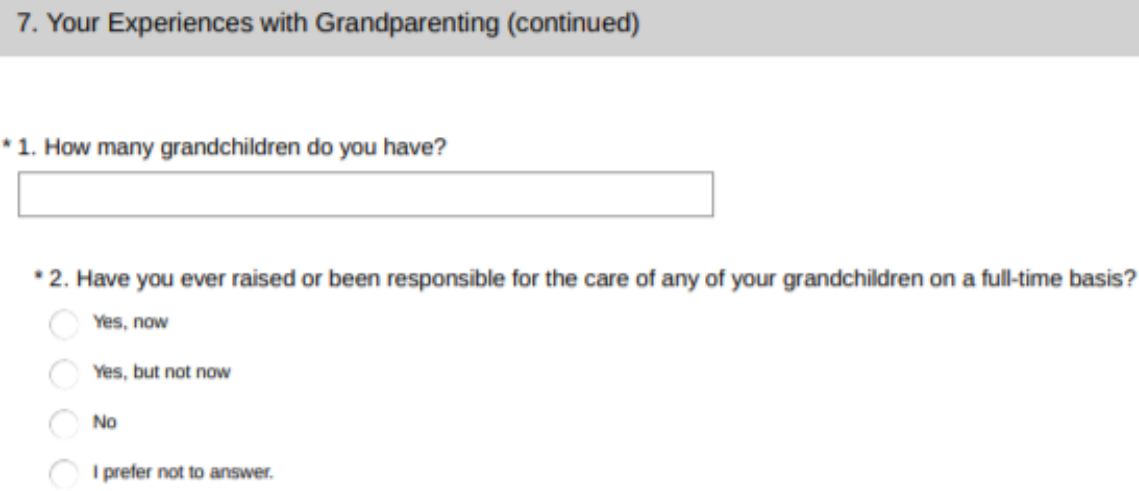

*3. In the past 6 months, how many hours per week did you spend with one or more grandchildren during the summer?

* 4. In the past 6 months, how many hours per week did you spend with one or more grandchildren during the school year? 


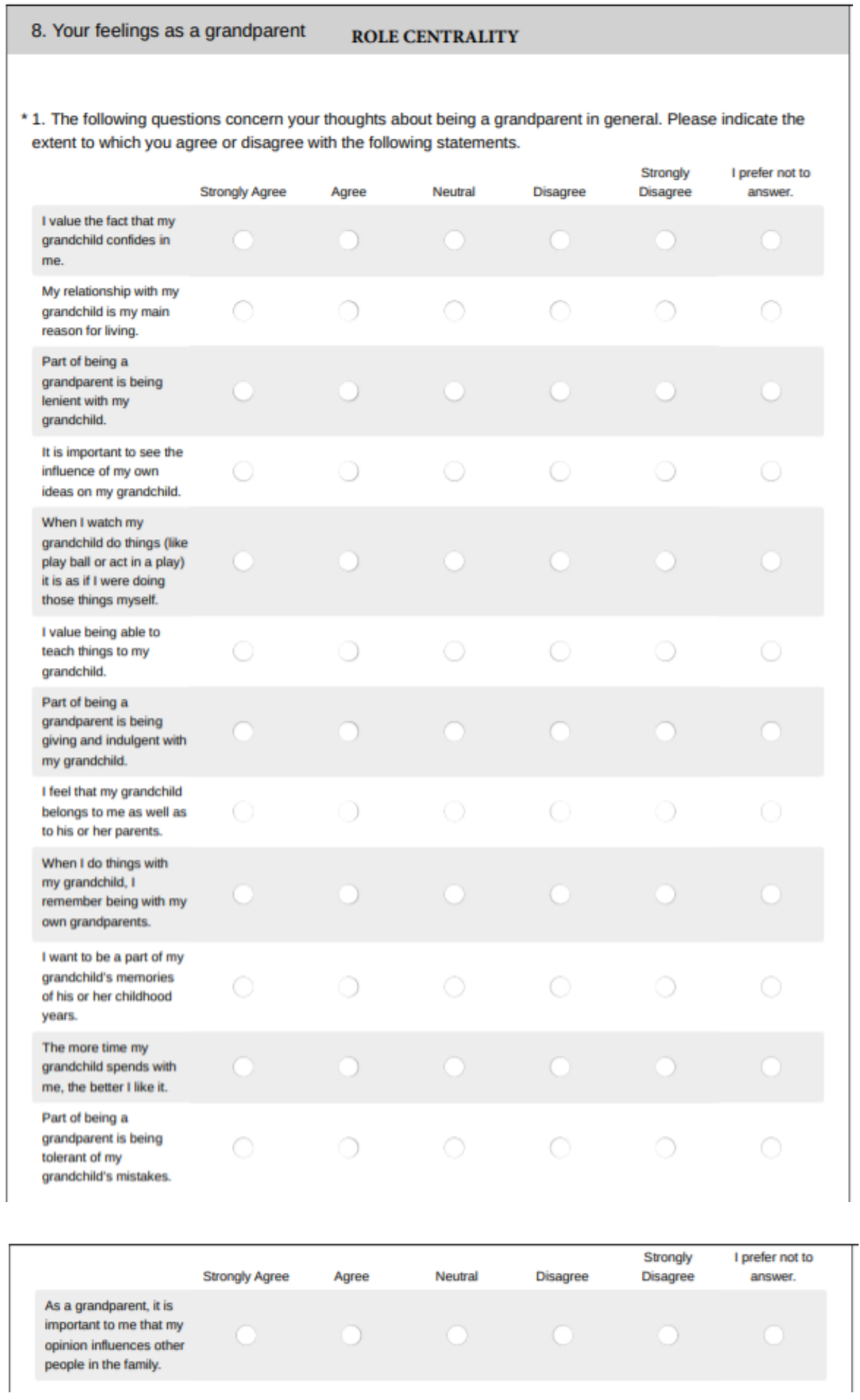




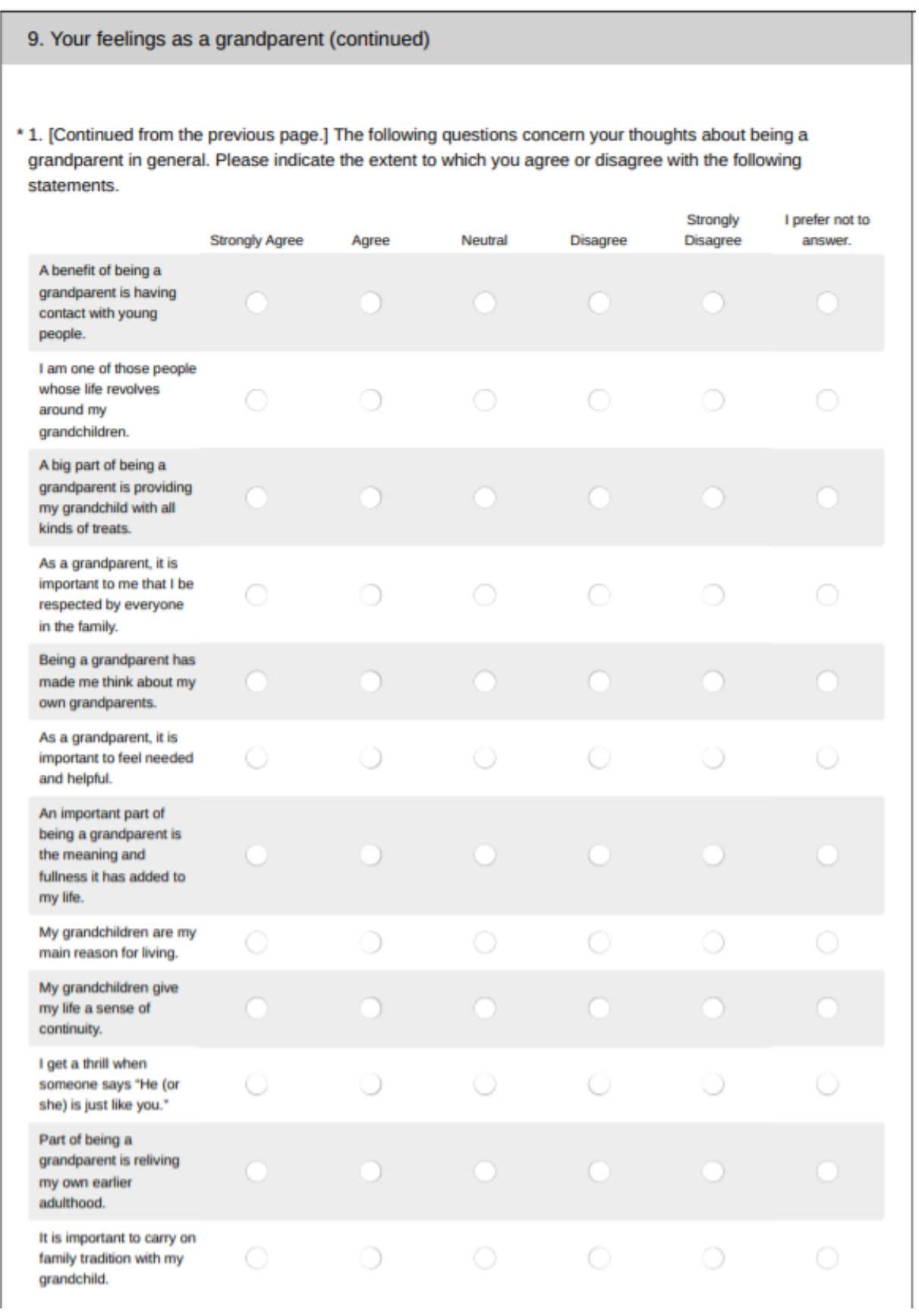

Grandparenthood is
NOT the most important
thing in my life.
My grandchild is
important because he or
she is the one who will
carry on the tamily line.
It is important to me that
my grandchild sees me
as someone special.




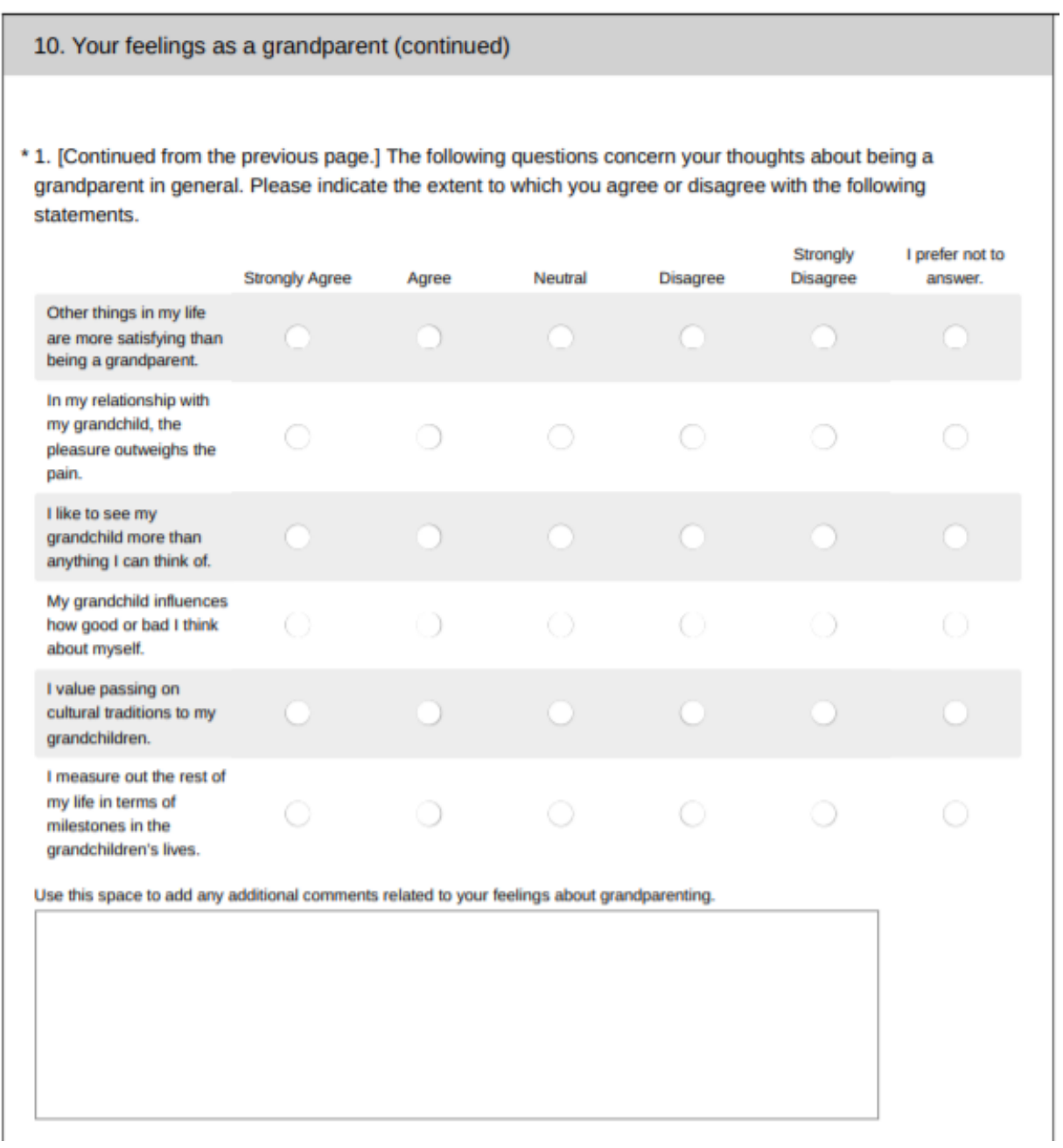




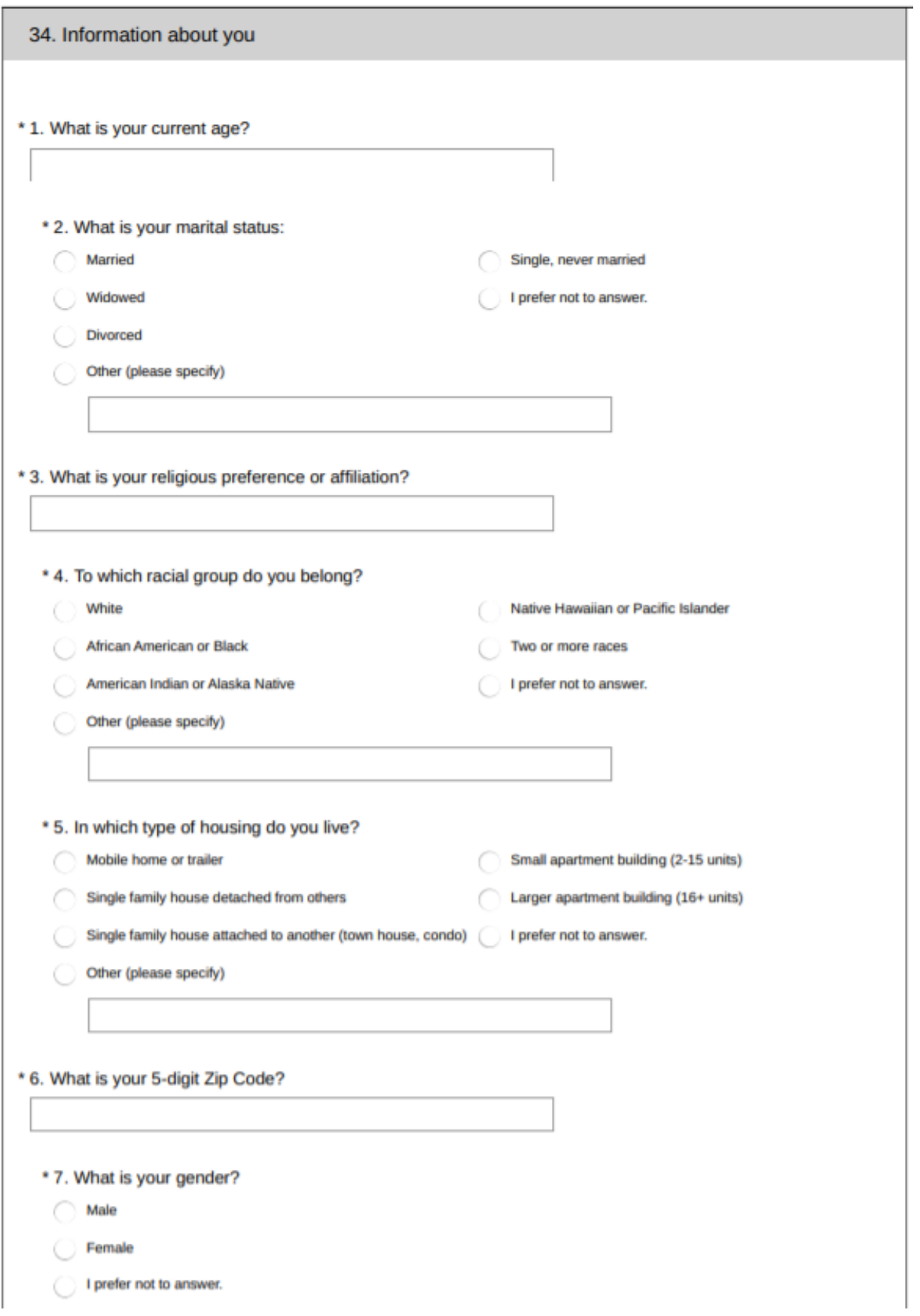




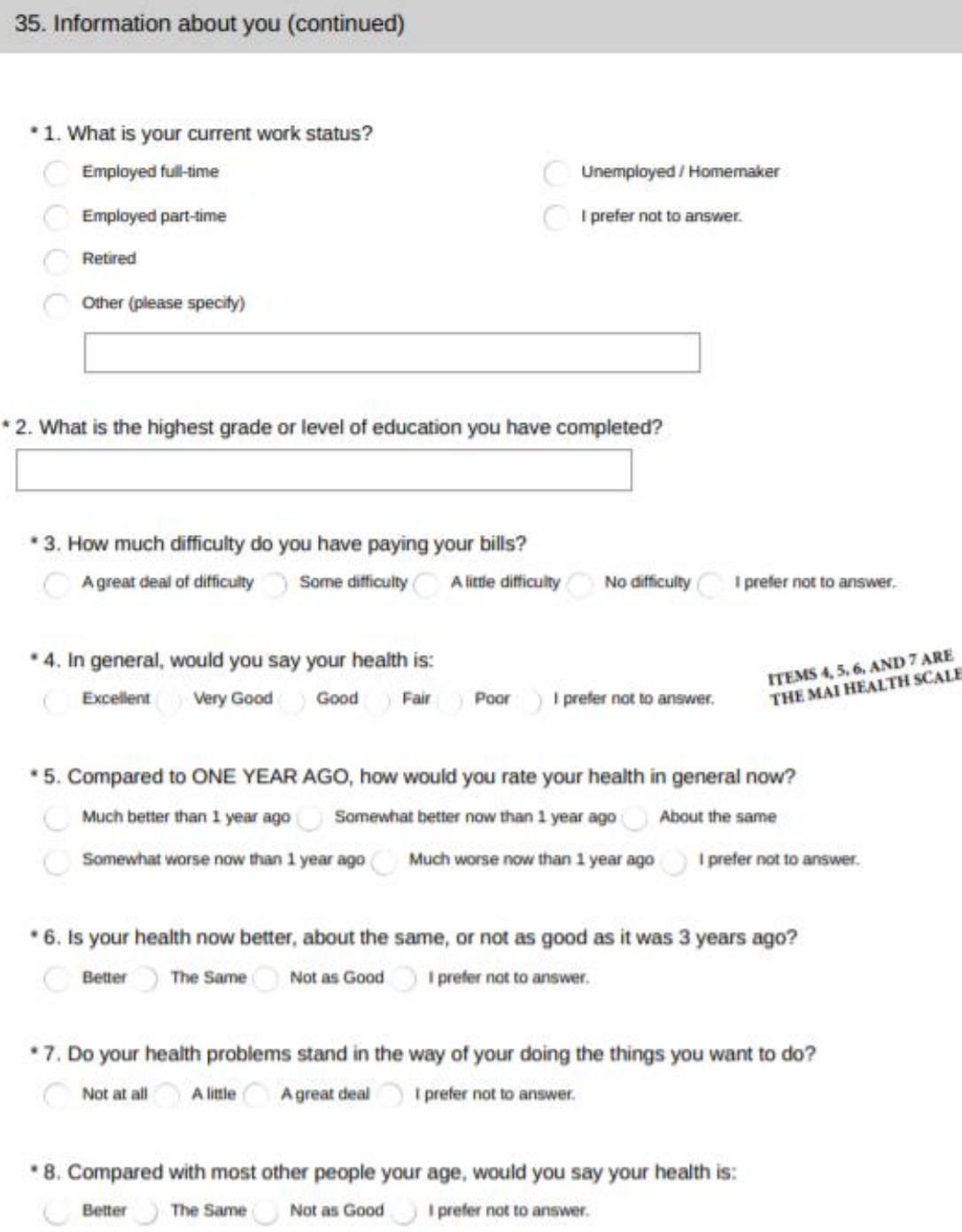

-3. How much difficulty do you have paying your bills?

A great deal of difficulty Some difficulty A little difficulty No difficulty I prefer not to answer.

-4. In general, would you say your health is: $\quad$ TTEMS 4, 5, 6, AND 7 ARE Excellent Very Good Good Fair Poor i prefer not to answer. THE MAI HEALTH SCAL

*5. Compared to ONE YEAR AGO, how would you rate your health in general now? Much better than 1 year ago Somewhat better now than 1 year ago About the same Somewhat worse now than 1 year ago Much worse now than 1 year ago I prefer not to answer.

- 6 . Is your health now better, about the same, or not as good as it was 3 years ago? Better The Same Not as Good I prefer not to answer.

*7. Do your health problems stand in the way of your doing the things you want to do? Not at all A litie A great deal I prefer not to answer.

-8. Compared with most other people your age, would you say your health is: Better The Same Not as Good I preter not to answer. 


\begin{tabular}{|c|c|c|c|c|c|}
\hline \multicolumn{2}{|c|}{ 40. Health Conditions (continued) } & \multicolumn{3}{|c|}{ CESD Depression Scale } & \multirow[b]{3}{*}{$\begin{array}{l}\text { I prefer not to } \\
\text { answer. }\end{array}$} \\
\hline \multicolumn{5}{|c|}{ *1. For the following statements, please indicate how you have felt in the LAST WEEK. } & \\
\hline & Rarely & Sometimes & Occasionally & Most & \\
\hline $\begin{array}{l}\text { I was bothered by things } \\
\text { that usually don't bother } \\
\text { me. }\end{array}$ & O & $\mathrm{O}$ & O & O & 0 \\
\hline $\begin{array}{l}\text { I did not feel like eating: } \\
\text { my appetite was poor. }\end{array}$ & 0 & $\mathrm{C}$ & P & O & $\mathrm{O}$ \\
\hline $\begin{array}{l}\text { I felt that I could not } \\
\text { shake off the blues even } \\
\text { with help from my family } \\
\text { or friends. }\end{array}$ & O & O & 0 & 0 & O \\
\hline $\begin{array}{l}\text { I felt that I was just as } \\
\text { good as other people }\end{array}$ & & $\mathrm{C}$ & & & \\
\hline $\begin{array}{l}\text { I had trouble keeping my } \\
\text { mind on what I was doing }\end{array}$ & O & O & O & O & $\mathrm{O}$ \\
\hline I felt depressed. & $\circlearrowleft$ & $\circlearrowleft$ & 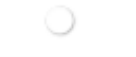 & $\cup$ & \\
\hline $\begin{array}{l}\text { I felt everything I did was } \\
\text { an effort. }\end{array}$ & 0 & $\mathrm{O}$ & O & O & 0 \\
\hline $\begin{array}{l}\text { I felt hopeful about the } \\
\text { future. }\end{array}$ & $\cup$ & $\cup$ & $\circlearrowleft$ & $\cup$ & $\mathcal{U}$ \\
\hline $\begin{array}{l}\text { I thought my life had } \\
\text { been a failure. }\end{array}$ & 0 & 0 & O & O & 0 \\
\hline I felt feartul. & & $\mathrm{C}$ & 0 & & \\
\hline My sleep was restless. & & O & ) & () & \\
\hline I was happy. & & $\mathrm{C}$ & ?) & & \\
\hline I talked less than usual. & 0 & $\mathrm{O}$ & O & 0 & 0 \\
\hline I felt lonely. & & $\mathrm{C}$ & P & 0 & \\
\hline People were unfriendly. & 0 & 0 & 0 & 0 & 0 \\
\hline I enjoyed life. & 0 & $\mathrm{C}$ & D & & $\bigcirc$ \\
\hline I had crying spells. & O & $\mathrm{C}$ & O & 0 & 0 \\
\hline I felt sad. & $\circlearrowleft$ & C & $\mathcal{J}$ & $\cup$ & $\circlearrowleft$ \\
\hline $\begin{array}{l}\text { I felt that people disliked } \\
\text { me. }\end{array}$ & $\mathrm{O}$ & $\mathrm{O}$ & 0 & O & O \\
\hline I could not get "going". & $\circlearrowleft$ & $\mathcal{C}$ & $\circlearrowleft$ & & \\
\hline
\end{tabular}

